Revista UNIVERSUM · No 26 • Vol. 1 • 2011 · Universidad de Talca

Libertad e igualdad. Una aproximación a la noción de justicia social en la izquierda chilena del siglo XX

Paula Vidal Molina

Pp. 169 a 204

\title{
Libertad e igualdad. \\ Una aproximación a la noción de justicia social en la izquierda chilena del siglo $\mathrm{XX}^{1}$
}

\author{
Paula Vidal Molina $\left(^{*}\right)$
}

\section{RESUMEN}

Se realiza una reconstrucción teórica acerca de la noción de justicia social presente en tres tradiciones de la izquierda chilena: el Partido Comunista, el Partido Socialista y el Movimiento de Izquierda Revolucionaria (MIR). La historia de estas colectividades es abordada desde principios del siglo XX, pero especialmente a partir de la década del 50 hasta el golpe militar del año 1973. Los hallazgos dan cuenta de que la noción de justicia social de las tres corrientes tiende a coincidir y sustentarse en la dialéctica necesidad/libertad.

\section{Palabras clave:}

Izquierda chilena - justicia social - partido comunista - partido socialista - MIR.

\footnotetext{
(*) Magíster en Antropología y Desarrollo, Universidad de Chile. Doctora (c) en Serviço Social, Universidade Federal de Río de Janeiro. Académica de la Universidad Católica Cardenal Raúl Silva Henríquez.

Artículo recibido el 18 de octubre de 2010. Aceptado por el Comité Editorial el 11 de abril de 2011.

Correo electrónico: pvidal71@yahoo.com

${ }^{1}$ Agradezco los comentarios a los historiadores Sergio Grez y Claudia Drago.
} 


\begin{abstract}
We present a theoretical reconstruction of the notion of social justice, present in three traditions of the Chilean left: Communist Party, Socialist Party and the Revolutionary Left Movement (MIR). The history of these groups is considered from the start of the XX centuary, but especially since the 50's until military coup in 1973. The findings show that: the notion of social justice of three groups tend to coincide and is sustained by is dialectic need/freedon.
\end{abstract}

Key words:

Chilean left - social justice - communist party - socialist party - MIR.

\title{
1. Introducción
}

Las definiciones que se han dado de la justicia social han ido variando a lo largo de las épocas y de acuerdo a las circunstancias. Sin embargo, en esta variedad subyace algo común y universal que permanece por encima de las singularidades históricas. Siguiendo a Ernest Mandel (2001), la historia muestra una larga serie de revueltas que se elevan contra la desigualdad social y la injusticia, afirmando con ello el deseo de justicia social, es decir, de una sociedad más igualitaria ${ }^{2}$. Uno de los aspectos fundamentales de esa lectura, es que ratifica la relación entre lo particular y lo universal, entre la estructura y la historia como componentes de una totalidad ${ }^{3}$.

Para algunas corrientes, las ideas -en sí mismas- presentan elementos intemporales, de aplicación universal lo cual hace que no sea necesario considerar la realidad contingente en la cual surgieron ${ }^{4}$. Pero la dificultad -como bien lo plantea Skinner- al centrar la atención solo en lo que se dice y no en el contexto en que se produjo, hace

${ }^{2}$ Ernest Mandel identifica sucesivas revueltas periódicas de los explotados y oprimidos en la historia, tanto en el Egipto faraónico como en "las revueltas de esclavos en la Grecia y la Roma antiguas, entre las cuales la dirigida por Espartaco durante el primer siglo de nuestra era fue la más célebre. Después ocurren los poderosos movimientos de esclavos que contribuyen para la caída del Imperio Romano, las de las bagaudas en la Europa occidental y de los donatistas en el África del norte. La India y principalmente la China clásica fueron marcadas por innumerables revueltas campesinas, entre ellas varias victoriosas, y que dieron origen a nuevas dinastías imperiales. En Japón, en la época de los Tokugawa, ocurrieron entre 1603 y 1863, más de 1.100 revueltas campesinas. La Rusia zarista también conoció numerosos levantamientos campesinos, de los cuales el más célebre fue el de Pougatchev en Ucrania, en el siglo XVII. En la América colonizada por los españoles y portugueses, los indios sometidos a la servidumbre y los esclavos se rebelaron frecuentemente. La más conocida de esas revueltas fue la de los indios de Perú, dirigida por Tupac Amaru a mediados del siglo XVIII. Hubo la revuelta victoriosa de los esclavos negros de Haití, los jacobinos negros, al final del siglo XVIII. Ocurrieron numerosas revueltas de esclavos negros en el siglo XIX en América del Norte, principalmente la dirigida por Nat Turner en 1831. En la Europa occidental y central una serie casi ininterrumpida de jacqueries (revueltas campesinas como la dirigida por John Ball, en Inglaterra, en 1381) y levantamientos de artesanos y aprendices contra el dominio de la nobleza y de los comerciantes ricos se extienden desde el siglo XIII al XVI. Ellas desembocan en las grandes revoluciones burguesas, en los Países Bajos, en Inglaterra, en Estados Unidos y en Francia". (Mandel, Ernest; 2001, pp. 48-49). Traducción propia.

${ }^{3}$ Adscribimos al principio de totalidad como una de las principales características metodológicas de la reflexión marxista acerca de lo social, en palabras de Carlos Nelson Coutinho "Esa decisiva indicación metodológica, recogida por el marxismo de la herencia dialéctica de Hegel, significa la necesidad de concebir la sociedad como totalidad, esto es, como una realidad compleja y articulada, formada por mediaciones, contradicciones y procesos (...) Lo que caracteriza metodológicamente el pensamiento marxiano es, por lo tanto, la insistencia en la necesidad de concebir la vida y las estructuras sociales reconociendo, por un lado, que ellas forman objetivamente una totalidad, pero también, por otro lado, que el modo más correcto de comprenderlas subjetivamente en la adopción consciente de lo que el joven Lukács llamó de punto de vista de totalidad". (Coutinho, Carlos Nelson; 1994/2008, pp. 92 - 93) Traducción propia.

${ }^{4}$ Isaiah Berlin es uno de los exponentes de este tipo de corriente. 
"corre(r) el riesgo de caer en varios tipos de absurdo histórico" (Skinner, Quentin; 2000, p. 152). Para evitar aquello, alienta en que es necesario asumir -para el estudio de las ideas- el contexto social o condiciones históricas en que aparece. En este sentido es posible afirmar que las ideas tienen historia. Pero, rechazamos también caer con el peso de la historia en la explicación y configuración de las ideas en un contexto preciso, lo cual impide una construcción interpretativa singular con vocación de traspasar el contexto que explica su aparición. Metodológicamente intentaremos buscar los hilos que se mantienen y con los cuales podemos construir la noción de justicia social, en la historia de una cierta región de la política de la izquierda chilena.

Asumimos que diversas instancias, históricamente situadas, han usado la noción de justicia social. Hoy a nadie extraña que diversos ámbitos de la sociedad movilicen declaraciones y promesas de un futuro "mejor" a partir de esa palabra, o desde la "injusticia social" evidencien aquello que detestan y resisten padecer. Hurgar en el significado, en lo que refiere, cuál es el aparato conceptual que sostiene esas declaraciones y el proceso histórico concreto en que se inscribe, así también cuáles arreglos ideológicos y político-programáticos se desprenden de esto es lo que intentamos realizar.

Partimos de la hipótesis de que los arreglos ideológicos y político-programáticos sustentan ciertas -y en algunos casos escasas- elaboraciones teórico/conceptuales, por ello, tales arreglos no se desprenden exclusivamente de los avatares cotidianos, ni de las fuerzas y juegos de poder existentes en el proceso de su elaboración. Existe una relación -no siempre del todo clara- entre elementos conceptuales y circunstancias (o contextos históricos en que se producen), como también -por parte de algunos autores- el ejercicio de retomar problemas y temas del pasado re-significándolos para el momento actual, influenciando la elaboración político-programática. Creemos, que la justicia social puede ser un buen ejemplo de esa mixtura.

La intención que nos mueve es adentrarnos en un espacio delimitado geográfica, política y cronológicamente con el fin de comprender la noción de justicia social como parte de una totalidad que indudablemente no alcanzaremos. Nuestro escenario será el mundo de la izquierda chilena, porque ésta ha ejercido una influencia decisiva en la evolución política y conformación de la realidad del país. Al mismo tiempo, pensamos que a través del rescate y reconstrucción de los sentidos que le asigna la izquierda chilena a la Justicia Social en diversos momentos históricos, permitirá evaluar críticamente y disputar los sentidos que se le asignan en el debate contemporáneo.

Nos centraremos en la izquierda chilena del siglo XX, hasta el año 1970. La razón de ello, responde a que posteriormente a los años treinta la izquierda se centra fuertemente en los Partidos Socialista y Comunista, gozando de un espacio claro y de alianzas en el escenario político nacional, pero a partir de los años sesenta, coexisten estos partidos con otras agrupaciones políticas que serán nuevas versiones de esa constelación de izquierda. Sin embargo, es necesario reconocer que a partir de los años sesenta la izquierda chilena se amplía tanto en lo que agrupaciones políticas se refiere como a su vínculo con la sociedad civil. Recordemos que el respaldo electoral 
osciló entre un 30\% y un 50\% entre 1958 y 1973 para la izquierda concentrada en los Partidos Socialista y Comunista. También surgen nuevos movimientos producto de la izquierdización de sectores de la Democracia Cristiana -el Mapu y la Izquierda Cristiana-, como de las juventudes de los partidos socialistas y comunistas que darán origen al Movimiento de Izquierda Revolucionaria - MIR. Nuestro límite cronológico son los años setenta porque luego del golpe militar la estructura política, económica, social y cultural tanto del país como a nivel internacional varía de tal modo que la izquierda tradicional se reconfigura tanto en sus alianzas como en las temáticas que abordará.

Sabemos que hoy la izquierda es más social que partidista y, por lo mismo, su encarnación a través de los partidos políticos está lejos de interpretar del todo a la ciudadanía que se siente de izquierda. Diversos son los grupos y movimientos sociales cuyas acciones concretas les permite ir ubicando un nicho de acción al interior de la sociedad. Sin embargo, hemos elegido profundizar sobre los grupos que se autodefinen como partidos políticos y como movimiento (pero que se estructuran internamente como partido político), debido a que aún logran articular un discurso común al interior del segmento en cuestión, movilizando acciones tensionantes del estatu quo, a contrapartida del discurso común que aún no logran articular los grupos y movimientos, donde la fuerza discursiva se disuelve en la diversidad y fragmentación de sus opiniones. Insistimos en la izquierda partidista porque en varios momentos históricos ha gestado coaliciones y programas de acción donde un número importante de ciudadanos se ha sentido representado.

No podemos negar que en el transcurso del siglo XX la izquierda se transformó, después de los años treinta, con la aparición del Partido Socialista. Luego, en los años sesenta adquiere un nuevo matiz con la aparición de varios grupos izquierdistas junto a los procesos internacionales que contribuyen a ese proceso. Después del golpe militar como también posteriormente a los años noventa alcanza nuevos tenores. En ese sentido, no es fácil definir la izquierda chilena como una unidad continua. Sabemos que es arriesgado asumir una definición ya que en ese mismo acto se construyen límites que tienden a invisibilizar los matices, las mixturas y los procesos.

Bajo dichas debilidades y considerando que los límites están lejos de ser fijos, adscribimos a la idea de Perry Anderson (2008) de que se trata más bien de un espectro en que se debe tener presente las ideas en juego del otro campo para poder medir las del propio. En este caso la izquierda se define también en relación con las ideas del campo correspondiente al "centro" y a la "derecha". Reconocemos la pertinencia de esto último en el desarrollo que presentamos a continuación, pero también las actuales restricciones para realizar ese itinerario.

Adscribimos a la idea presente en Bobbio de que "izquierda" no es un concepto que indique una identidad política substantiva, es decir, un programa político determinado con un contenido fijo, sino que -en sintonía con Perry Anderson- es un concepto relativo cuyos contenidos adquieren sentido en la relación con otro, en este caso, la "derecha", pero que igualmente presenta un contenido determinado y constante en el tiempo, lo cual lo salva de cualquier relativismo. 
No lograremos dar con una única definición de izquierda. Por lo mismo, decidimos rescatar algunos elementos de a lo menos tres versiones, que nos parecen relevantes a la hora de pensar la izquierda chilena. La primera planteada por Jorge Castañeda (1993), de la cual extraeremos la parte que refiere al criterio ideológico y político, en donde la izquierda se puede descomponer en: a) partidos comunistas tradicionales, b) las organizaciones político-militares, y c) los reformistas. Agrega también un criterio funcional donde incorpora el grupo de la izquierda social y la izquierda intelectual ${ }^{5}$, pero en la que no profundizaremos debido a la dispersión de organizaciones, grupos y sujetos que la conforman.

A la vez, Castañeda (1993), apunta algunos elementos que nos parecen pertinentes para definir el campo de la izquierda y que podemos resumir en lo siguiente: priorizan la ruptura por sobre la continuidad; la democracia y los derechos humanos sobre la seguridad nacional, la identidad nacional y la soberanía sobre la integración económica. En el ámbito económico-social, se insiste en: la justicia social sobre el desempeño económico, la distribución del ingreso sobre el buen funcionamiento de los mercados, reducir la desigualdad más que en la competitividad, el gasto social sobre el control de la inflación, la necesidad del gasto sobre el imperativo de saneamiento de las finanzas del gobierno.

Por otro lado, la definición enunciada por Norberto Bobbio acerca de algunos elementos que permiten seguir creyendo en que es posible distinguir entre derecha e izquierda, señala que la izquierda se ha caracterizado por guiar su preocupación por la igualdad, es decir, la estrella polar que ha guiado a la izquierda es el ideal de la igualdad, la tendencia a remover los obstáculos que hacen a hombres y mujeres menos iguales.

Un último elemento que parece importante destacar para configurar una definición de la izquierda es que aún teniendo presente que en la actualidad la izquierda ocupa un lugar de menor protagonismo que en tiempos anteriores, es posible concebirla como aquella que -en el decir de Perry Anderson (2008)- a pesar de ser vencida no ha inclinado la cabeza ante los vencedores. En ese sentido, la tradición del materialismo

\footnotetext{
${ }^{5}$ Castañeda, define 4 grupos para el criterio ideológico político: Comunistas, nacionalistas, militares y reformistas. Los partidos comunistas serán aquellos que mantendrán vínculos con la Unión Soviética y asumirán "la vía pacífica al poder". La izquierda nacionalista o popular será entendida en relación a diversos líderes como Getúlio Vargas en Brasil, Lázaro Cárdenas y Torrijos. Esta vertiente -la nacional populista de izquierda- según el consenso historiográfico chileno, no tuvo presencia importante al interior de la izquierda, excepto si consideramos la observación de Paul Drake (1992) quien plantea que existió en la primera etapa de formación del Partido Socialista -los años 30-, pero que en el corto tiempo se reordenará en función de enfatizar elementos ideológicos marxistas como el conflicto de clases, en vez de la política personalista, paternalista, el eclecticismo ideológico o el pragmatismo. Pero aún con esa observación, creemos que el desarrollo de los grupos políticos de izquierda chilenos permite excluir ese componente para delimitar el objeto de estudio. Los grupos y organizaciones político-militares surgen especialmente después de la Revolución Cubana, adhieren a la lucha armada y son afines ideológicamente con Cuba y Fidel Castro. La izquierda reformista poseen una vocación electoral, se distancian de la Unión Soviética y Cuba, y enfatizan la democracia, los derechos humanos y la justicia social. La izquierda social que no solo incluye a los sindicatos obreros tradicionales, ligas y organizaciones campesinas, iglesias y comunidades eclesiales de base, cooperativas y marginales urbanos organizados sino también incorpora grupos de mujeres, ecologistas, indígenas y asociaciones de derechos humanos. La izquierda intelectual "-escritor, sacerdote, periodista, académico, artista, activista- ha solido desempeñar un papel clave. El intelectual articula con frecuencia las demandas nacionales, sociales y democráticas del pueblo o de la región a través de la prensa, la academia, el gobierno y en el exterior. Aunque no dejan de estar expuestos a la acusación de una representación falsa o exagerada, los intelectuales, conocidos y anónimos por igual, son parte esencial de la izquierda latinoamericana" (Castañeda, J. 1993, p. 23). Los grupos trotskistas y maoístas junto a la izquierda cristiana forman también parte de la izquierda latinoamericana.
} 
histórico está lejos de incorporarse a la lógica del consenso y en eso la historia del movimiento obrero de principios del siglo XX, con el Partido Comunista y Socialista chileno, junto al MIR hasta los años setenta, dan cuenta de esa tradición.

Para aproximarnos a desarrollar lo que hemos planteado es necesario recoger $\mathrm{y}$ dilucidar brevemente en la bibliografía chilena del siglo XX, aquellos elementos y procesos que dan cuenta de la emergencia de la preocupación por la justicia social especialmente por parte de colectividades y grupos de sujetos que lo pondrán como tema público. Luego brevemente transitaremos al interior de las colectividades partidarias de la izquierda que hasta los años sesenta se situaban en los Partidos Comunista y Socialista (PC-PS), con el fin de ubicar algunos elementos que puedan ser interpretados bajo el concepto de Justicia Social. El mismo recorrido haremos a partir de los años sesenta con la emergencia del Movimiento de Izquierda Revolucionaria (MIR).

Debemos prevenir a los lectores acerca de alguna intención de esperar una construcción y reconstrucción histórica, tanto de los partidos políticos como de la historia nacional e internacional, que cruza la vida de estas colectividades. El presente trabajo no es una historia de la izquierda chilena con sus influencias y discusiones nacionales e internacionales, sino una construcción que incorpora inevitablemente ese componente histórico para explicar procesos, pero puesto al servicio del análisis y reconstrucción de las ideas y valores que están detrás de los elementos empíricos puestos en cada programa de trabajo partidista o de coalición. Para ello, se eligen ciertos fragmentos a examinar pertenecientes a los Programas de Coalición y declaraciones de los Partidos Políticos, con ello se hace luego un trabajo interpretativo que permitirá mirar esos procesos y elementos empírico-pragmáticos bajo el prisma de los valores y dimensiones que conforman la justicia social para esa izquierda chilena.

\section{Breve referencia a los orígenes de la Izquierda Chilena 1850-1930: la Cuestión Social}

La Sociedad de la Igualdad de 1850, fundada por Francisco Bilbao y Santiago Arcos adquiere ese nombre debido a la importancia que alcanza esa palabra como heredera de la Revolución Francesa y de los eventos del " 48 " parisiense. Asimismo, se habla de que la Sociedad fue la confluencia del ideario del "pipiolaje criollo más radical, con elementos ideológicos republicanos y populistas tomados del imaginario del " 48 " europeo y de algunos autores liberales, católicos-sociales y socialistas utópicos" (Gazmuri, C. 1998, p. 73). Sus integrantes fueron principalmente artesanos y liberales (en esa época liberal era asociado a revolucionario) por lo tanto, se encontraba lejos de ser una organización principalmente obrera o de conducción popular. Sin embargo, la estructura y sus actividades daban cuenta de su preocupación por mejorar las condiciones de la clase obrera, especialmente a través de cursos que impartieron gratuitamente a los artesanos.

Francisco Bilbao definiría los objetivos de la Sociedad de la Igualdad años después de la fundación de ésta como 
“emancipación del pensamiento, emancipación del ciudadano, emancipación del proletariado; revolución de la razón en la política, en la distribución de la propiedad; derecho de ser y pensar por sí mismo; derecho de gobierno en cada hombre, universalidad del crédito; independencia de la razón; la soberanía del pueblo; crédito social y asociación. En otros términos: libertad, democracia, solidaridad. He ahí el fondo y el horizonte de la revolución. Tal fue el alma de la Sociedad de la Igualdad" (Francisco Bilbao en Cristian Gazmuri; ídem, p. 95) 6

Definición bastante amplia, pero que deja entrever una preocupación de los intelectuales y elite del pensamiento emancipatorio, por establecer condiciones que permitan a las personas un mayor grado de dominio sobre sus vidas tanto en lo material como en el ámbito de la razón.

A poco andar esta organización fenece debido a la represión ejercida por parte del gobierno de Montt -representante del autoritarismo conservador- quien deja en la ilegalidad esta organización, persiguiendo a sus militantes ${ }^{7}$.

El movimiento desarrollado por la Sociedad de la Igualdad permitió que varios artesanos y sujetos no pertenecientes a la clase aristócrata de la época se movilizaran por cuestiones públicas. Sin embargo, lo que se refiere como cuestión social -sin el uso de ese nombre en la época- aparece en Chile en el primer proceso industrializador antes de $1880^{8}$ y es entre los años de 1860 y 1870 el punto de conjunción entre el viejo modo de producción colonial y aquella cuestión social gestada con el paso al modo de producción capitalista, donde aparecieron los temas de emigración de trabajadores de las zonas rurales, problemas de insalubridad, hacinamiento y precariedad del hábitat popular, miseria, alimentación insuficiente traducida en elevadas tasas de mortalidad, especialmente infantil. Las transformaciones sociales y económicas producto de la incipiente industrialización y la incorporación de la nortina región minera de Tarapacá, a la economía chilena, incidieron en ir generando la constitución del proletariado.

Las Sociedades de Socorros Mutuos, las cooperativas, las mancomunales y las sociedades de resistencia fueron los medios para enfrentar corporativa y cooperativamente los rigores del capitalismo en el país, no solo con funciones de asistencia y socorro mutuo, sino también movilizando a los asociados en momentos

\footnotetext{
" Para mayor detalle Sobre la Sociedad de la Igualdad, ver Carta de Arcos a Bilbao. Sergio Grez "La cuestión social en Chile. Ideas y Debates Precursores (1804-1902)". Centro de Investigaciones Diego Barros Arana y Dirección de Bibliotecas, Archivos y Museos. Santiago de Chile. 1995.

${ }^{7} \mathrm{El}$ ambiente de la época de 1850 y la revuelta de 1851 donde integrantes de la Sociedad de la Igualdad participan, es reflejada en la narrativa de Alberto Blest Gana, Martín Rivas, en ella se conjugan las diferencias de clases sociales, la participación política y el amor entre Martín -digno representante de un provinciano de clase media- y Leonor hija de la oligarquía santiaguina.

${ }^{8}$ Hacia el año 1865 la población urbana aumentó de un 25\% a un 43\% en 1895, concentrándose principalmente en dos ciudades: Santiago y Valparaíso. Sergio Grez menciona que el desarrollo del sector artesano-industrial posibilitó a partir de los años sesenta que parte de los inmigrantes hacia las ciudades no se viera condenada a ingresar a las filas del peonaje, sumado a la Guerra del Pacífico y el aumento del crecimiento del mercado interno incentivaron la expansión de la producción fabril, "Una de las consecuencias sociales de estos procesos fue el surgimiento de una embrionaria burguesía industrial, cuyos núcleos más significativos continuaron siendo durante todo el siglo XIX, extranjeros o descendientes directos de extranjeros. Esta nueva clase manifestaba su deseo de lograr mejores condiciones políticas y económicas para su progreso. Consciente de su importancia, imbuida de su misión "progresista" y "civilizadora", la naciente burguesía industrial chilena se organizó y movilizó a partir de los años setenta, para obtener del Estado ayudas y mayores facilidades para sus actividades fabriles y comerciales, coincidiendo, a menudo en sus demandas de proteccionismo con las organizaciones de obreros y artesanos" (Grez, S. 1997, p. 122).
} 
de huelga. Es sabido que los problemas de salud, vivienda, educación, producción y empleo se intentaban solucionar a través de las propias organizaciones de trabajadores y artesanos mucho antes de que el Estado comenzara a desempeñar sus funciones reguladoras de la fuerza laboral (Varas, 1988; Illanes, 2007). Este movimiento de masas organizado en torno de metas sociales fue determinante para el aparecimiento de concepciones socialistas, más allá de que trajeran incorporados -en la memoria colectiva- el ideario igualitarista de Francisco Bilbao y Santiago Arcos.

El programa y manifiesto del Partido Democrático en 1887 es uno de los primeros documentos de una organización política chilena en que se plantea la solución integral de las injusticias y la desigualdad social, "El Partido Democrático tiene por objeto la emancipación política, social y económica del pueblo" (Grez, S., 1997, p. 27). Pero la cuestión de la relación entre el capital y el trabajo si bien es denunciada, no es abordada -según Sergio Grez- por ninguna medida específica en el programa del Partido Democrático ${ }^{9}$, cosa que si incorporará la tradición que se inaugura con la formación del Partido Socialista y la vertiente anarquista de fines del siglo XIX.

Sibien, la izquierda chilena tradicionalmente se forjó al alero de los Partidos Comunistas y Socialistas, la historiografía ha entregado antecedentes suficientes para entender el rol protagónico que tuvieron los anarquistas desde fines del siglo XIX hasta los años treinta del siglo XX, en el movimiento social de trabajadores ${ }^{10}$, mujeres, pobladores e intelectuales ${ }^{11}$ al interior de la izquierda chilena y latinoamericana ${ }^{12}$. En ese sentido, la

${ }_{9}^{9}$ Sergio Grez identifica al Partido Demócrata como el primero en desplegar esfuerzos para avanzar hacia la legislación social y de crear un paquete de proposiciones legislativas. Malaquías Concha en 1901 habría presentado un proyecto de reglamentación del trabajo que contemplaba condiciones generales de seguridad, reglamentación laboral, inspección e indemnización por accidentes. Frente a ello, los anarquistas se posicionaban incrédulos y rechazaban estas proposiciones de legislar bajo las condiciones de dominación burguesa, situación que también ocurría con un ala del mismo partido Democrático. Ver Grez, S. "El escarpado camino hacia la legislación social: debates, contradicciones y encrucijadas en el movimiento obrero y popular (1901-1924). Ubicado en http://www.bibliotecaobrera.cl/wp-content/uploads/2009/03/ legislacion-social.pdf . Revisado el 15 de abril de 2009.

${ }^{10}$ Según Sergio Grez, los anarquistas chilenos tomaron los discursos, análisis y propuestas típicas del movimiento libertario internacional que llegaron desde Europa, Argentina y Perú a través de periódicos, libros, folletos, inmigrantes, viajeros. Ya en el año 1902, los anarquistas habían ganado influencia en los trabajadores ferroviarios, gráficos, tranviarios, carpinteros, zapateros y panaderos de Santiago, como también en la Federación obrera (de carbón) de Lota y Coronel, como en Valparaíso, Viña del Mar y el norte del país. Grez, Sergio: Los anarquistas y el movimiento obrero. La alborada de “la idea" en Chile, 1893-1915. Editorial LOM, Santiago de Chile, 2007.

${ }^{11} \mathrm{El}$ anarquismo también influenció a intelectuales y al movimiento estudiantil. Entre los primeros se pueden mencionar la generación literaria del veinte con Manuel Rojas, José Santos González Vera y José Domingo Gómez Rojas, este último muerto en 1920 después de las secuelas que le ocasionara la brutal tortura a que fue expuesto por el gobierno de la época. Cada uno de ellos se aproxima al mundo del proletariado y la marginalidad social representados a través de las figuras del conventillo, o personajes como ladrones, pescadores, bohemios, anarquistas, obreros revolucionarios. Los cuentos de Manuel Rojas -como exponente de la tendencia del realismo urbano- muestran crudamente la forma de vida de los marginales, por ejemplo, la situación de hambre, el llanto, la vulnerabilidad y caridad en que se desenvuelve el protagonista de "El vaso de Leche". La pobreza, el alcohol y el robo como parte del paisaje cotidiano del conventillo en que vive el protagonista peluquero retratado en el cuento "El Delincuente". El estado de padecimiento de la suerte que le toca a la mujer -en "Un ladrón y su Mujer"- en que no ve más posibilidad que vivir la cárcel y el abandono de parte de su marido ladrón como muestra de su capacidad de sacrificio y fidelidad por el amor que siente por él. O aquel solitario paciente convaleciente recién salido del hospital que no le quedó más posibilidad que hacerse mendigo en vez de irse al Hospicio. Todos sus cuentos relatan una situación de pobreza que afecta la dignidad de los protagonistas, presentándose como seres disminuidos, pero que asumen sin mayor reclamo, sin ese sentimiento de injusticia que moviliza el cambio de su situación de vida individual y colectiva.

${ }^{12}$ Luis Vitale apunta las influencias de los anarquistas en América Latina, menciona que el anarco-sindicalismo fue una corriente importante del movimiento obrero latinoamericano durante las dos primeras décadas del siglo XX, contribuyendo a formar las primeras organizaciones clasistas y a crear una conciencia anticapitalista. Sin embargo, su crisis se gesta al mismo tiempo en que aparecen los primeros gobiernos populistas en América Latina, los cuales introducen reformas sociales para canalizar el descontento obrero. Para mayor detalle ver Luis Vitale, “Contribución a una Historia del Anarquismo en América Latina". Instituto de Investigación de Movimientos Sociales "Pedro Vuskovich". Santiago. Chile, 1998. Ubicado en http://www.scribd.com/doc/8944386/-Luis-Vitale-Contribucion-a-una-historia-del-anarquismo-enAmerica-Latina, visitado el 15 febrero de 2009. 
izquierda chilena se gestó a la luz de los acontecimientos que iban sucediendo desde fines del siglo XIX y principios del XX en Chile, pero que respondían a un proceso histórico de mayor orden en los países centrales y al influjo que iba adquiriendo el pensamiento de la época en Chile y América Latina ${ }^{13}$.

Los primeros exponentes de las ideas socialistas ${ }^{14}$ en Chile, aparecen previamente a la actuación en 1896 de agrupaciones de carácter socialista: el Centro Social Obrero y la Agrupación Fraternal Obrera que en un año se fusionarían -debido a las coincidencias en sus objetivos y accionar- dando origen a la Unión Socialista y en 1898 al Partido Socialista que no vivió más de un año. Es necesario mencionar que socialistas y anarquistas tendrían un origen común, en la Unión Socialista, ya que originariamente la tendencia anarquista en Chile -según Sergio Grez- fue poco definida y difícilmente distinguible de los socialistas. Ya en esa época es posible identificar en las declaraciones públicas el uso de la palabra injusticia como una especie de denuncia de las condiciones de vida paupérrimas en que habitaba la mayoría de la población y trabajadores del país producto de las condiciones laborales en que se desempeñaban. La invitación que hacían era a sumarse a ese descontento a través de las organizaciones de resistencia y luchar por la emancipación que solo se lograría rompiendo con el régimen capitalista de su tiempo.

Para Devés y Díaz (1987) el programa del Partido Socialista de 1898 dejaba clara su inspiración en la filosofía materialista, el proyecto revolucionario y el afán emancipatorio, junto con su crítica a la ideología opresora y la reivindicación de mejores condiciones de vida y trabajo ${ }^{15}$.

Asimismo, por el lado de los anarquistas de principios del siglo XX -siguiendo a Sergio Grez (2007)- estuvieron ligados fuertemente al movimiento obrero, algunos pregonando la violencia revolucionaria como único medio de cambio social, y otras vertientes anarquistas pacifistas que veían en la huelga, el boicot y la propaganda medios de transformación social. Independientemente del modo de accionar, los anarquistas tenían la convicción de que los problemas sociales no tenían solución

\footnotetext{
${ }^{13}$ Parece ser consensuado que la recepción de la obra de Marx en América Latina se ubica en las tradiciones de la Segunda Internacional que construirá una lectura de Marx tributaria del clima cultural dominante desde la segunda mitad del siglo XIX. Escritos socialistas serán traducidos al castellano por José Mesa y los socialistas de Madrid, llegando a América Latina, "junto a la literatura que alimentaba a los grupos libertarios, a través de los bagajes de la migración y de las pasarelas que representaron intelectuales vinculados a las tradiciones socialistas, como Germán Ave Lallemant y Juan Bautista Justo, o de periódicos como el Socialista que, desde 1886, editaba Pablo Iglesias en Madrid. (...) Serán estas las claves de lectura las que, atravesando el Atlántico, estimularán a las nacientes organizaciones de trabajadores latinoamericanos, dándole forma a concepciones programáticas que, privilegiando el papel de los sectores antagónicos al interior del modo de producción , van a mostrar dificultades para analizar la complejidad de la formación económico-social sobre la cual se proponen actuar" (Massardo, Jaime; 2007, p. 123).

${ }^{14}$ Eduardo Devés identifica a Víctor José Arellano Machuca -publicista- como el primer chileno que publica textos donde utiliza los conceptos de "socialismo" y "socialista" de modo sistemático, no anclando este en un accionar de partido político ni de organización obrera. En su folleto de 1893 “El catolicismo y el Socialismo" si bien es un texto que rebatirá la postura de la Iglesia católica de la época, inaugura una línea de pensadores socialistas. Para mayor detalles ver Eduardo Devés y Carlos Díaz “El Pensamiento Socialista en Chile. Antología 1893-1933". América Latina Libros. Ediciones Documentas, Chile, 1987.

${ }^{15}$ El Programa mínimo del Partido Socialista chileno de 1898 incluía la supresión del trabajo nocturno en los talleres y fábricas, o en su defecto, doble remuneración; a igualdad de producción, igualdad de salario; creación de consejos departamentales de representantes elegidos de los patrones y trabajadores y rentados por el Estado a fin de ejercer vigilancia en las fábricas y solucionar los conflictos del trabajo; igualdad de instrucción y de derechos civiles entre hombres y mujeres, supresión de los ejércitos permanentes, entre otras cosas. Para mayores detalles ver Programa Mínimo del Partido Socialista Chileno, el Martillo, Santiago 3 de julio de 1898, en Eduardo Devés y Carlos Díaz, 1987.
} 
dentro del capitalismo y solo una reforma social radical resolvería esa cuestión;

"los libertarios se encaminarían por la vía de la acción directa en el desarrollo de las luchas populares con una perspectiva que -al menos en teoría- suponía la huelga general revolucionaria, la eliminación inmediata del Estado y la instauración de la sociedad anarquista o comunista libertaria. Los socialistas, en sus distintas variantes, optarían por una estrategia de reformas que si bien no excluía las luchas de clases, las subordinaba a una política que implicaba la participación en las instituciones estatales para utilizarlas en beneficio de los intereses populares" (Grez, S., 2007, p. 42).

La influencia en la intelectualidad obrera chilena, estuvo dada -entre otras cosas- por la lectura suficiente o insuficiente de algunas obras de pensadores como Bakunin, Proudhon, Ruskin, Tolstoy, Kropotkine, Marx, James, Nordau, Engels, George, Lenin, Dostoiewsky, Trotsky, Saint Simon, Iglesias, Malatesta, Costa, Bebel, Ferri, Eliseo Reclus, Juan Grave, Sebastián Faure y Drapper, obras vendidas en librerías de las ciudades más grandes de Chile como Antofagasta, Valparaíso, Concepción, Valdivia, Magallanes y Santiago. Según Guillermo Feliú (1950)

"las editoriales españolas de Sopena, Aguilar, Gili, Suárez, Rodríguez, Maucci, Salvat, Espasa lanzaron en Chile un género de literatura social explotada en la novela, en el drama, y en el cuento, que dejaba en el fondo de las conciencias un eco de rencor, contra el rico, contra los bancos, contra medio capitalista, contra las prerrogativas de la alta aristocracia, amparada en la Iglesia, y contra la injusta sujeción a que se encontraban sometidos, humillados y escarnecidos, los elementos del pueblo" (Feliú en Cruzat y Tironi; 1999, p. 129) ${ }^{16}$.

Para Augusto Varas, la izquierda chilena se reproduce en un medio de masas altamente movilizadas debido a la

“temprana ampliación del espacio político interno (que) permitió que estas masas se expresaran, si bien con dificultades, en términos estatales a través de representantes políticos Radicales o Demócratas en el Parlamento de la época. Esta característica propia del Estado demoliberal que se gesta en el país en el siglo pasado posibilita que en el momento de ascenso de masas el movimiento popular no se enfrente a un despotismo de clases desnudo, sino a un sistema más evolucionado que lo habilitaba para desplegar su iniciativa dentro de él" (Varas, A., 1988, p. 18).

Para este autor, el factor de la amplitud del espacio político en el parlamento, explica que la izquierda ligada a ideales socialistas pudo tener representantes propios en la primera década del siglo XX.

\footnotetext{
${ }_{16}$ No obstante la efervescencia social y la acción de los grupos de izquierda, la lectura de estos teóricos y literatos, no se puede dejar de mencionar la influencia que pudo ejercer sobre algunos intelectuales y sujetos políticos en la primera mitad del siglo XX la literatura hispanoamericana de la época. José Portuondo (1972) menciona que se ha reconocido a la novela como expresión de la realidad geográfica, física, social, psíquica. En ese aspecto, la novela hispanoamericana se ha generado principalmente de la realidad social y a la vez incidido en ella. En literatura chilena se reconocerá que la generación del 38 es la que verá en el quehacer literario una función social, tomando posición respecto al mundo y al proletariado, época en que también los Partidos Comunista y Socialista se han consolidado en el mundo popular. Fernando Alegría, Guillermo Atías, Oscar Castro, Francisco Coloane, Carlos Droguett, Juan Godoy, Nicomedes Guzmán, Reinaldo Lomboy, Volodia Teitelboim, entre otros, son algunos que la conforman.
} 
Es de consenso en la historiografía chilena decir que a comienzos del siglo XX cristalizó una crisis económica, social y política. Entre las causas que se mencionan (Devés, 1999, Jocelyn-Holt et al, 2001; Gazmuri, 2001) podemos señalar: la transformación de los hábitos de la burguesía hacia la ostentación y el lujo producto de la riqueza del salitre; los problemas en el gobierno por el régimen parlamentario que profundizó los problemas nacionales, la desvalorización permanente del peso provocando un creciente empobrecimiento de los grupos proletarios y de sectores medios generando gran agitación social, como también las sistemáticas crisis económicas internacionales repercutiendo en quiebras y cesantía en el país, junto a las precarias condiciones de vida del proletariado ${ }^{17}$.

La economía chilena dependía principalmente de sus exportaciones mineras a mercados externos -cobre y salitre-, lo cual le dejaba en una posición absolutamente frágil frente a los avatares de la economía mundial.

Estos elementos fueron conformando y delimitando la cuestión social en el pensamiento de los intelectuales y obreros en Chile ${ }^{18}$, que en la izquierda tomaría forma -como ya mencionamos- en los grupos anarquistas y anarcosindicalistas, pero también en sindicatos de trabajadores como la Federación Obrera de Chile (Foch) creada en 1909 y que en 1919 adopta una posición marxista, siendo liderada por Luis Emilio Recabarren.

La Foch muestra unos principios en los que se reconoce la preocupación existente respecto de las condiciones sociales y materiales de los trabajadores. En ese sentido, se evidencia una preocupación no solo por la protección social de los trabajadores sino también por el desarrollo de estos de modo integral: educación, salud, los intereses morales, elementos que interpretamos ligados a la justicia social. Ellos declaran en los Principios de 1919:

\footnotetext{
${ }^{17}$ Es interesante cómo Cristián Gazmuri en su texto "El Chile del centenario, los ensayistas de la crisis", muestra que ellos -entre 1900 y 1920- denunciaron la crisis nacional profunda en un momento en que pocos compartían esa opinión. Enrique Mac Iver, Emilio Rodríguez Mendoza, Alberto Edwards, Nicolás Palacios, Tancredo Pinochet, Alejandro Venegas, Francisco A. Encina, Luis Emilio Recabarren, Agustín Ross, Guillermo Subercaseaux, entre otros, no los unía ni la clase social a la que pertenecían, ni la corriente ideológica a la que adscribían, es decir, su observación de la crisis no era "fruto de un compromiso político o doctrinario claro, sino resultado de una actitud emotiva de los autores frente a su observación de la realidad chilena. Son individualidades que manifiestan la existencia de una crisis latente, la que no era percibida por el grueso de la opinión pública del país, pero que existía como quedó demostrado cuando la crisis se actualizó en los años 1924-1925". Para algunos de estos ensayistas es una crisis moral, para otros una de desarrollo y social, algunos creen que es producto del sistema político, otros que se debe a una crisis de la educación o que es producto de los problemas económicos monetarios. Pero lo que uniría a todos ellos, es la importancia que le otorgan al elemento representado por la relajación moral de la clase alta chilena de la época. Ver detalles en Gazmuri, Cristián: “Los "autoflagelantes" de 1910 Bicentenario. Centenario y reflexión. El Mercurio, publicado el 16 de Diciembre de 2001. Ubicado en http://www.archivochile.com/ Historia_de_Chile/otros_artic/HCHotrosart0017.pdf ,revisado 15 de abril de 2009.

${ }^{18}$ Cruzat y Tironi (1999), Gazmuri (1999) mencionan que la conceptualización de la cuestión social no es propia del mundo obrero chileno de la época, sino que es un término cuyo origen se encuentra entre los intelectuales y reformadores europeos, ligados a la izquierda. Estos textos se conocen en Chile alrededor de los años ochenta del siglo XIX. Así, la cuestión social no fue exclusivamente trabajada por el mundo obrero, sino también por intelectuales y hombres de acción pertenecientes a diversas corrientes ideológicas, las cuales Cruzat y Tironi agrupan en tres grandes líneas: 1.- Corriente conservadora-católica -de criterio eticista- que le asignan a los individuos y a la clase dirigente en sus deberes y derechos, un lugar fundamental para enfrentar la cuestión social, 2.- Corriente radical-reformista y nacionalista, donde le asignan al Estado un rol primordial y 3.- Corriente demócrata-socialista, cuyo rol protagónico frente a la cuestión social lo tiene el Pueblo.
} 
“La Federación Obrera de Chile se ha fundado para realizar los siguientes propósitos: Defender la vida, la salud y los intereses morales y materiales de toda la clase trabajadora de ambos sexos.

Defender a los trabajadores de ambos sexos de la explotación patronal y comercial, de los abusos de jefes y autoridades y de toda forma de explotación y de opresión.

Proteger a sus afiliados en todos los actos que establezcan sus estatutos.

Fomentar el progreso de la instrucción y cultura de la clase trabajadora por medio de conferencias, escuelas, bibliotecas, prensa y toda actividad cultural, y conquistar la libertad efectiva, económica y moral, política y social de la clase trabajadora (obreros y empleados de ambos sexos) aboliendo el régimen capitalista, con su inaceptable sistema de organización industrial y comercial, que reduce a la esclavitud a la mayoría de la población.

Abolido el sistema capitalista, será reemplazado por la Federación Obrera, que se hará cargo de la administración de la producción industrial y de sus consecuencias.

Estas aspiraciones serán sustentadas en realidad cuando la Federación Obrera de Chile por intermedio de todas sus secciones tenga la potencia suficiente para realizarlas.

Para librar a los trabajadores y empleados de ambos sexos de la explotación y opresión en que viven esclavizados, a medida que el poder de la Federación lo permita se luchará: Por el mejoramiento de los salarios, de manera que correspondan a las necesidades de la vida de constante progreso, hasta producir la transformación del régimen del asalariado por un mejoramiento superior, que concluya con la esclavitud del salario.

Por la disminución de las horas de trabajo, como un medio de disminuir la desocupación y la fatiga, para darse tiempo a la vida societaria.

Por el abaratamiento de la vida, ya sea por medio de agitaciones, influyendo en la legislación de los impuestos, o creando o protegiendo instituciones cooperativas que tengan por objeto abaratar la vida.

Por desterrar en forma definitiva todos los vicios de la clase trabajadora, y el del alcohol y de los juegos de azar.

Por el mejoramiento de las habitaciones y su abaratamiento por los medios que la fuerza creciente de esta Federación le sea permitida.

Esta Federación será la escuela donde se moldee el mejor pensamiento que oriente al proletariado de ambos sexos a la perfección de su organización social e industrial, hasta obtener su integral emancipación.

Todo este programa de perfección social podrá cumplirse si la clase proletaria de ambos sexos (Obreros y empleados) se apresura a construir la fuerza capaz de realizar este programa, acudiendo a incorporarse previamente a la Federación Obrera de Chile, en cualquiera de sus secciones, sindicatos o federaciones que forman parte de esta organización que es la escuela práctica que enseña y dignifica, el más amplio concepto de la verdad y justicia social.

Por lo tanto la Federación Obrera de Chile, levanta su bandera, inspirada en estas dos profundas sanciones internacionales: "la unión hace la fuerza" y "la emancipación de la clase trabajadora debe ser obra de los trabajadores mismos" (Federación Obrera de Chile; 1919).

De lo anterior podemos decir que la justicia social presente a partir de esta declaración de la FOCH remite a un petitorio de condiciones que no solo intentan suplir la esfera de la necesidad, sino también la de la libertad, como dos momentos de una totalidad, permitiendo con ello superar las precarias condiciones de vida de los sujetos, especialmente hombres y mujeres trabajadores. Este último aspecto es interesante porque rescata un elemento de diversidad que tal vez para la época no era del todo 
legitimado en el mundo popular: las condiciones de las mujeres trabajadoras. Si entendemos el discurso de la FOCH acerca de la justicia social dialécticamente entre la esfera de la necesidad y de la libertad, tal noción se concreta -desde el ámbito de la necesidad- en la defensa de la salud, mejoramiento de salarios, finalización de abusos patronales, mejoramiento de habitaciones o viviendas de los trabajadores, el acceso a educación, y -desde el ámbito de la libertad- a través de la participación en la vida social y en la organización obrera, en la libertad política y social. Todos estos elementos son aspectos que configuran un concepto amplio de justicia social, en tanto no es una reducción a necesidades materiales. Otro aspecto fundamental a tener presente en este análisis es que podemos construir dos posibles caminos para interpretar la condición a priori necesaria para el desarrollo de la justicia social. Si bien, la FOCH se declara anticapitalista, y en el sendero de abolir el sistema capitalista para gestar un nuevo tipo de relación social y de justicia social, también es posible interpretar que el petitorio planteado son objetivos realizables en el capitalismo.

Luis Emilio Recabarren, en 1912 funda el Partido Obrero Socialista (POS) que en el año 1922 se transformará en el Partido Comunista Chileno ${ }^{19}$. Siendo él, líder del POS deja clara su posición incrédula respecto de la herramienta legislativa en pos de mejoras de las condiciones sociales de los trabajadores, influyendo en la permanente oscilación -del POS- entre la vía de integración o el rechazo al sistema legislativo como medio de mejoras para los trabajadores ${ }^{20}$. En ese sentido, la participación en el Parlamento por parte del POS, sería para mostrar al pueblo la incapacidad de la burguesía y la inutilidad de sus leyes.

Situación similar vivió el PC para la misma época de su fundación respecto de las leyes sociales, donde asume una posición intermedia entre los anarquistas y los demócratas;

\footnotetext{
${ }_{19}$ Dada la influencia de la Revolución Bolchevique, desde comienzos de los años veinte grupos de obreros comienzan a abandonar los partidos socialistas para fundar secciones de la Internacional Comunista. En noviembre de 1919 se funda el Partido Comunista de México, a fines de 1920 el Partido Socialista de Uruguay se transforma en Partido Comunista. En Argentina, donde en 1918 se había fundado el Partido Socialista Internacional, nace en enero de 1921, el Partido Comunista Argentino. En 1922 se funda el Partido Comunista de Brasil. En 1925 se funda el Partido Comunista de Cuba. En mayo de 1930, un mes después de la desaparición de Mariátegui, el Partido Socialista del Perú se transforma en Partido Comunista. (Massardo, ídem).

20 “QQuieren los obreros que vaya a la Cámara a hacer leyes obreras, opuestas a las leyes burguesas?

No. Ya comprendemos los obreros que el problema social no se resolverá por medio de las leyes, pues, la burguesía capitalista, jamás habrá de permitir que se hagan leyes benéficas para el pueblo y si algunas se hicieren no las respetará. Entonces, ¿para qué hacer más leyes? De la Cámara burguesa jamás saldrá una ley que determine la verdadera libertad, ni el verdadero bienestar y felicidad popular. Jamás. La historia del pasado es la prueba, porque jamás se ha hecho leyes que acaben con la esclavitud. Si la representación socialista fuera al Congreso a contribuir a la dictación de nuevas leyes, no iría a obtener a verdadera libertad que necesitamos, ni a obtener verdadero beneficio para la familia obrera. Cualquier ley que un diputado socialista obtuviera, con apariencias beneficiosas, no serviría para nada para el pueblo, puesto que nunca han servido y en cambio contribuiría a mejorar las condiciones del estado capitalista, postergando y retardando la verdadera emancipación popular, a la vez que haciendo confiar al pueblo en esperanzas que jamás se transformarán en bienestar social” Recabarren, Luis Emilio; 1921 reproducido en Grez, Sergio:“El escarpado camino hacia la legislación social: debates, contradicciones y encrucijadas en el movimiento obrero y popular (1901-1924). Ubicado en http://www.bibliotecaobrera. cl/wp-content/uploads/2009/03/legislacion-social.pdf . Revisado el 15 de abril de 2009.
} 
"Los comunistas no podían oponerse a leyes por las cuales habían luchado desde su militancia en el Partido Obrero Socialista. Sin embargo, tendían al escepticismo respecto de la posibilidad de su aprobación y puesta en práctica, sospechando que se trataba de un mecanismo para neutralizar al movimiento obrero. Su propia participación en el Parlamento era concebida como una táctica destinada a denunciar los vicios del sistema y difundir un discurso revolucionario. Recabarren pensaba que no valía la pena distraer muchas energías proletarias en una "cosa tan baladí, en una lucha estéril, inoficiosa y hasta enervante" ya que de ella no podía extraerse nada en beneficio de los trabajadores. Un parlamentario comunista iba a la Cámara "a destruir, a despedazar con su crítica libre y severa, la dialéctica jesuítica y sofística, de los representantes burgueses; y a iluminar, con el resplandor de la doctrina comunista los problemas vitales" (Grez, S., ídem, p. 39).

Indudablemente, Luis Emilio Recabarren será una figura importante en la época, por constituirse en uno de los exponentes de la izquierda de principios de siglo en que "la cuestión social" toma una dimensión central en sus escritos. Propone la agitación social que conduzca a una sociedad socialista, emancipada, donde reine la "justicia", el "amor verdadero" y el "perfeccionamiento individual y moral". Se logra interpretar en sus escritos elementos de justicia social, observa que una sociedad socialista conlleva una vida de goces, de rectitud moral, de educación y de bienestar que lo asocia a características económicas y sociales que hacen que las condiciones materiales en que viven los individuos estén muy lejos de la miseria. Lo anterior, solo es posible de conseguir en un tipo de sociedad no capitalista. Esto en palabras de Recabarren;

"Si el socialismo es la abolición de los imaginarios derechos sobre la propiedad privada, el socialismo se presenta entonces como una doctrina de la más perfecta justicia, de verdadero amor, y de progresivo perfeccionamiento individual y moral (...) es desde un punto de vista social, una doctrina de sentimientos de justicia y de moral, que tiene por objeto suprimir todas las desgracias ocasionadas por la mala organización de la actual sociedad para que la vida sea vivida en medio de goces perpetuos (...) Todos los vicios, todos los delitos, todos los crímenes, el inmenso desarrollo de la prostitución, son consecuencias de la mala constitución de los pueblos y de su tolerancia por los individuos que sufren las consecuencias (...) Socialismo es abolir la miseria, la ignorancia, la explotación, la tiranía, el vicio y todos los defectos humanos que el buen sentimiento y la educación puedan suprimir, es el progreso, es el bienestar, la alegría, el amor, la justicia, la comodidad, en fin todo aquello que ayuda a constituir el verdadero progreso del individuo y de la sociedad "(Recabarren, Luis Emilio; 1916 en Devés y Díaz; 1987, pp. 92-93).

Para Recabarren, entonces, las estructuras de las relaciones de producción del país exacerban la sobreexplotación del trabajador, denunciando al mismo tiempo con esto el carácter "injusto" e "inmoral" de ello. Podemos decir, que la justicia en la sociedad socialista implica cubrir la esfera de la necesidad y la libertad, la igualdad y libertad de condiciones sociales, económicas, culturales.

Para visualizar -por otro lado- la visión del PC acerca de la justicia social, es importante también revisar los Estatutos que éste se dio al momento de su fundación en tanto sintetiza su evaluación del momento histórico y de las ideas que guiarían 
la acción de sus miembros. En ello, nos encontramos con aspiraciones que también identificamos en los principios de la FOCH y en el programa del Partido Socialista de 1897: búsqueda de libertad, superación del sistema capitalista y condiciones sociales que permitan el desarrollo y emancipación de los hombres, mujeres y niños. En ese sentido, podemos pensar que lo que guía es aspirar a cubrir un nivel de necesidades materiales e inmateriales (trabajo digno, salud, educación, ciencia y arte) que permitan el desarrollo de los hombres y mujeres en su calidad de sujetos dignos e iguales. La lucha por la libertad es también otro componente importante, no solo de los ciudadanos en un régimen democrático, sino también como país respecto de otros. Identificamos la esfera de la necesidad, la igualdad y libertad, como formando parte de una totalidad. Pero la dimensión de la igualdad no refiere a distribución solamente, sino a una igualdad radical sustentada en la abolición de todas las formas de explotación y opresión. Así lo observamos cuando escriben:

“(El PC chileno) lucha por la conquista de la plena independencia económica y política de Chile; por conseguir para el pueblo las garantías de la más amplia y efectiva democracia; por mejorar las condiciones de vida, trabajo y cultura de la clase obrera y toda la población laboriosa, hasta llegar a abolir todas las formas de explotación y opresión, (...) trabajará por poner término a la esclavitud y explotación del país por el capitalismo internacional y la oligarquía criolla (...) reivindicando el derecho a defender, por sobre toda otra consideración, los supremos intereses del pueblo de Chile, su plena existencia como tal, su libertad y su porvenir. (...) luchará con todos los medios a su alcance por el imperio de las libertades públicas y de las garantías ciudadanas inherentes a todo régimen de gobierno democrático (...) luchará por la defensa del hogar y de la familia, trabajando por que cada hogar se vea libre del asalto de la miseria y de las plagas que diezman a nuestra población y por que cada familia sienta la sana alegría de vivir (...) luchará, asimismo, por el enaltecimiento y emancipación de la mujer, otorgándole todos los derechos que le son negados; luchará por la joven generación sumida en la orfandad y el desamparo; luchará por el desarrollo de la cultura, la ciencia y el arte (...) trabajará sin descanso por la unidad de la clase obrera y por la unidad nacional, enarbolando como su lema: CHILE PARA LOS CHILENOS" (Estatutos Partido Comunista de Chile; 192?, pp. 4-5).

La noción de justicia social que se desprende de esta declaración es una noción compleja, que -como ya mencionamos- incorpora dialécticamente la dimensión de necesidad y libertad, pero ella se enriquece cuando observamos detenidamente la existencia de bienes primarios a repartir ${ }^{21}$ como las libertades básicas, la renta y la riqueza, pero especialmente para los trabajadores, las mujeres, las niños y sus familias. Sin duda que estos recursos pueden ser obtenidos en una sociedad que supere el

\footnotetext{
${ }^{21}$ Lo mencionado nos hace recordar elementos que podemos identificar en la obra de Rawls, sabemos que podemos correr un riesgo en la interpretación, con el afán de incorporar en el análisis dimensiones teóricas y temporales diversas, como son los elementos históricos concretos chilenos y la dimensión teórico-filosófica construida en otro momento y espacio histórico. Sin embargo, no podemos desconocer que a pesar de la absoluta diferencia de la naturaleza de ellos, existen confluencias entre las declaraciones partidistas-políticas y la elaboración rawlsiana en lo que a los bienes primarios a repartir y el segundo principio de diferencia presente en la "Teoría de la Justicia". Como sabemos él menciona que los bienes sociales a distribuir son los derechos, las libertades básicas, libertad de circulación, libre elección, de ocupación de diversos contextos de oportunidades, poderes y prerrogativas de cargos y posiciones de responsabilidad en las instituciones políticas y económicas de la estructura básica, renta y riqueza, son solo algunos de estos. Y entre las libertades básicas tenemos el derecho a voto, desempeñar puestos públicos, de expresión, de reunión de conciencia, de pensamiento personal o de opresión psicológica, de agresión física, de propiedad personal, la distribución del ingreso y la riqueza, el diseño de organizaciones que hagan uso de las diferencias de autoridad y responsabilidad.
} 
capitalismo.

No podemos cerrar este punto sin sintetizar en que la época de principios del siglo XX, el conflicto político y social es lo que va a caracterizar el fenómeno societal chileno, lo cual permite en ese momento visibilizar con mayor claridad -a modo de una línea divisoria- a dominados y dominantes, explotados y explotadores, lo que se rechaza y lo que se acepta, las utopías a forjar. En ese aspecto, el movimiento socialista y comunista se erige fundamental para configurar parte de la realidad social e histórica de la época, incidiendo también en los procesos políticos y sociales futuros. Situación que en el contexto de América Latina no fue muy distinto, según Modonesi

"el movimiento socialista y comunista fue el acontecimiento del siglo. En América Latina, fue el eje a partir del cual se ordenó la realidad histórica; se politizaron las masas que irrumpieron en la escena, nacieron los movimientos populistas (...), se levantaron todos los principales movimientos de protesta, se reelaboraron los repertorios de la acción política, los referentes simbólicos de la lucha social, se resignificó la idea de revolución, se reformaron los Estados capitalistas oligárquicos, se derechizaron las fuerzas armadas, se reformuló la política norteamericana para la región" (Modonesi, M. 2007, p. 58).

\section{La Izquierda Chilena entre 1930 y 1960: Primacía del Partido Comunista (PC) y el Partido Socialista (PS)}

Tomás Moulian (2006) nos habla de que el sistema de partidos a partir de 1932 cambia radicalmente a como se estructuraba anteriormente y el síntoma de ese cambio aparece en el espectro político con el fenómeno de la polaridad. La izquierda marxista comienza a tener significación electoral, aumentando con ello la distancia ideológica y antagonismo entre los extremos. Esta distancia entre los partidos convive con la existencia de partidos intermedios o de centro que permitirán que el sistema político no sucumba. El Partido Radical será aquella agrupación de centro que tendrá un rol fundamental en gestar una alianza con la izquierda y regular los conflictos entre los extremos ideológicos partidistas. Por su parte el PC y PS conformarán la izquierda en el extremo ideológico.

El PC chileno, fundado en 1922, para fines de los años veinte se divide en un ala estalinista y una trotskista. La corriente trotskista pasará a formar parte del naciente Partido Socialista (en 1933), a mediados de la década del treinta junto a grupos de tradición anarquista.

Respecto del PC, entre los años 1922-1952 se habla de que su política se puede dividir en 4 etapas (Gómez, María Soledad; 1988) las cuales refieren a: el Frente Único y Revolución Socialista (1922-1933), Frente Popular y Democracia Burguesa (19331941), Unión Nacional (1941-1945 ) y Lucha de Masas (1945-1952). A grandes rasgos repasaremos esas etapas de modo de fijar las influencias y preocupaciones por los que el partido pasa, a modo de configurar el contexto que posteriormente conformará las alianzas entre los partidos PC y PS. 
Sin embargo, creemos que es importantísimo observar con mayor detalle los Programas construidos tanto en el Frente Popular como posteriormente, porque ellos muestran los puntos en los que se logró llegar a acuerdos al interior de una alianza constituida por diversas agrupaciones centro-izquierda. Así mismo, detenerse en el Programa de Emergencia -del PC- o en el Programa de Liberación Nacional, como aquellos que estarán detrás de aquel del Frente de Acción Popular (FRAP) es interesante para notar las influencias de que se nutrió el FRAP, como también lo que deja de esas influencias en función de lograr acordar un Programa en el que deben confluir diversas orgánicas ideológico-políticas.

La etapa del Frente Único del PC se corresponde con sus inicios en Chile en 1922 en las que se originan tensiones "entre las tradiciones ideológicas de origen popular presentes en el Partido Obrero Socialista que le dio origen y el marco eurocéntrico de la Internacional Comunista". En esa tensión de tradiciones, el PC define en esta etapa la lucha por el socialismo, diseñando la estrategia de alianzas que incluye al proletariado, al campesinado y al Partido, aplicando así la tesis del Frente Único Proletario recogida de la Internacional Comunista (Komintern), fundada en 1919.

El paso a la etapa de Frente Popular y Revolución Democrático Burguesa en 1933 es dado tras un proceso de autocrítica de la política anterior. Destaca por parte del PC, la necesidad de culminar las tareas -para Chile- de industrialización y modernización correspondientes a la etapa capitalista, antes de que sea posible pensar en una etapa superior de organización. Para ello, cree que las burguesías nacionales tienen un papel importante para lograr el desarrollo capitalista. En función de eso, se plantea formar un bloque abierto, donde se incorpore el sector revolucionario de la burguesía, arrastrando tras de sí -en la lucha contra el imperialismo- a la pequeña burguesía urbana y rural bajo la dirección de la clase obrera.

En este mismo período el Partido Socialista se ha fundado recientemente (1933), a partir de que a comienzos de los años 30 nacían varios grupos socialistas conformados por intelectuales y obreros ${ }^{22}$. Las acciones de estos grupos, junto al descontento de los militares más jóvenes y al de la población, producto de las consecuencias de la crisis del año 1929 y del gobierno de turno, derivó en un pronunciamiento militar que instauró la República Socialista en 1932 cuya duración no fue más de 12 días y cuyo lema declaró: "Pan, Techo y Abrigo para el Pueblo" como horizonte de lucha.

El PS rápidamente se transformó en un partido de masas declarándose marxista, anticapitalista, antifascista y antiimperialista, oponiéndose a la socialdemocracia y a la III Internacional. A diferencia del PC, abogaba por un Frente Único de Trabajadores donde debían participar los partidos y organizaciones obreras. Su identidad requirió diferenciarse del PC en tanto fuerza de izquierda más antigua.

\footnotetext{
${ }^{22}$ Algunas de las agrupaciones que se forman se encuentra el Partido Socialista Marxista, la Nueva Acción Pública, el Orden Socialista, el Partido Socialista Unificado y la Acción Revolucionaria Socialista (Witker, 1993).
} 
En sus Principios y Programa menciona que:

" 6 ' Chile soporta una doble explotación: la de la clase capitalista nacional y la del imperialismo extranjero. Se entrelazan en él, las formas y relaciones de producción semifeudal, derivados de la Colonia, y las formas y relaciones de producción capitalistas desarrolladas por la burguesía nacional y la penetración imperialista. Es un país semifeudal y semicolonial en donde el latifundio, la industria incipiente de sostenimiento artificial, y la dependencia del capital extranjero, entraban todo verdadero progreso.

El socialismo lucha por conseguir (...) desarrollar las fuerzas productivas, a superar el atraso social, técnico y cultural, y a eliminar la subordinación económica. El socialismo lucha por llevar a cabo una reforma agraria que suprima el latifundio y modernice la agricultura; por el control de las inversiones imperialistas y la nacionalización de los servicios de utilidad pública; por la industrialización que permita el aumento cuantitativo de las fuerzas productivas, y por la transformación cualitativa de la estructura económica. En esta forma el Estado y la democracia adquieren una nueva significación acorde con la realidad social y se lograría el bienestar de las grandes masas trabajadoras". (...)

Los graves problemas existentes imponen la reestructura económico-social del país, mediante una economía planificada de Estado, como una transición hacia un sistema socialista que logre

"los objetivos que las clases dominantes han frustrado. El desarrollo histórico del país impone la transformación de una economía semifeudal y semicolonial, orientada, con criterio liberal capitalista, a una economía superior, planificada, de espíritu y orientación socialista, tendiente a superar el atraso imperante e inspirada por una finalidad de servicio social. Esta economía planificada de Estado, en su primera fase, supone una amplia reforma agraria y una vasta industrialización (siderurgia, industria del cobre, de la madera, del carbón, de la pesca, química, energía eléctrica, industrias de alimentación y vestuario, vivienda popular) como un proceso dialéctico que comprende simultáneamente el incremento cuantitativo de las fuerzas productivas y la transformación cualitativa de la estructura económica, con lo cual el Estado y la Democracia adquieren una nueva significación El programa socialista pretende desarrollar la economía y lograr el progreso material de la comunidad; consolidar una amplia democracia social, donde existan el respeto a las libertades, la justicia económica y la disciplina colectiva e individual; además, la lucha permanente por el ennoblecimiento espiritual del hombre". (Principios y Programa del Partido Socialista 1933 en Witker, 1993, pp. 66-72).

Tal declaración de principios es clara en enunciar su rechazo al sistema capitalista y la necesidad de generar, por un lado, una economía planificada y el desarrollo industrial y agrario del país capaz de proveer el progreso material o las condiciones materiales de la comunidad, especialmente de la clase trabajadora que es aquella clase que sufre la desigualdad con respecto a la burguesía. Se trata entonces del progreso de la situación de éstos, pero en el horizonte de la igualdad, donde se incluye la justicia económica. Por otro lado, los principios muestran, la necesidad de fomentar y fortalecer la entrega de bienes sociales, especialmente lo que refiere a las libertades básicas, el desarrollo espiritual y el respeto se tornan parte de la consolidación de la 
democracia social. En ese sentido, podemos interpretar que la justicia social para el PS se compone de la dialéctica entre necesidad y libertad, recursos y bienes primarios que deben ser obtenidos por la clase trabajadora que sufre desigualdad en relación a la burguesía y los terratenientes, como también consolidar la libertad a través de la democracia, la participación política y la disciplina individual y colectiva. Todo ello sería posible si es que se avanza hacia un sistema no capitalista.

Después de la creación del PS, y más allá de las diferencias con el PC, éste último propone la creación del Frente Popular que será integrado -a partir de 1936- por el Partido Radical, el Partido Democrático y luego por el Partido Socialista, junto a la Central de Trabajadores de Chile y la Izquierda Comunista.

El Frente Popular llevó un candidato radical, Pedro Aguirre Cerda, a las elecciones de 1938, el cual resultó victorioso. El Programa de gobierno estaba basado en el fomento estatal a la industrialización -tema que tendrá importancia durante toda la década del $40-$ la protección de los trabajadores y la extensión de la cobertura en educación ${ }^{23}$. Interesante es observar que el Frente -como coalición de centro izquierda- asumió algunas tareas pendientes de la modernización capitalista, lo cual en palabras de Tomás Moulián (2006) "pone en funcionamiento una modalidad especial de la reproducción sistémica".

Sus tareas muestran la supremacía que debía asumir el Estado en las empresas donde el capital privado no estaba capacitado. Por lo tanto, el horizonte del Frente Popular

“No pretendía ni sustituir el capitalismo en el corto plazo, ni ser intransigente con las iniciativas de modernización (...) aunque los partidos de izquierda no abandonan, en función del presente, sus aspiraciones de futuro. Por lo tanto, no renuncian a la construcción socialista como horizonte e incluso justifican la estrategia actual en términos del futuro" (Moulian, T. 2006, p. 55).

Independientemente de que el gobierno del Frente tuviera o no la capacidad real de realizar el Programa propuesto, en lo que corresponde a nuestro objetivo acerca de la interpretación de la noción de justicia social, es importante analizar e identificar el planteamiento del Programa del Frente Popular:

"Este es un plan de acción común. Su lucha común debe traducirse primordialmente en una lucha organizada contra la opresión, el imperialismo y la miseria material e intelectual de las clases medias y obreras (...) $1^{\circ}$ Restauración de las libertades públicas en especial la de prensa, reunión, asociación y huelga y de las garantías individuales que estaban en las leyes del país. (...) $7^{\circ}$ Nacionalización y control estatal de nuestras fuentes naturales de riquezas (salitre, yodo, cobre, petróleo, carbón, caídas de agua, etc.) y de los servicios de utilidad colectiva (agua potable, alumbrado, fuerza y tracción eléctrica, ferrocarriles, teléfonos, etc.) (...) $12^{\circ}$ Reajuste de sueldos y jornales de empleos y obreros, públicos y privados, en proporción al descenso del poder adquisitivo de la

${ }^{23}$ En 1939 el nuevo gobierno del Frente Popular, creó la Corporación de Fomento de la Producción (CORFO), cuya tarea fue el fomento de la economía nacional en sus diversas áreas, mediante políticas públicas tendientes a fomentar la producción industrial y la modernización del sector agrícola. Se incentivó la substitución de importaciones de bienes intermedios y manufacturados, la construcción de infraestructura, instalación de industrias básicas, como también la construcción de escuelas. 
moneda, $13^{\circ}$ Salario mínimo por zonas y por ramas de trabajo, sin distinción de sexos, $14^{\mathrm{a}}$ Establecimiento de cajas de compensación de salarios familiares, $15^{\circ}$ Adopción de medidas para cumplir la obligación estatal de proporcionar trabajo al individuo en actividades productivas (planes de obras públicas, oficinas de colocación, intervención en la dotación de trabajadores de empresas particulares, etc.), (...) $18^{\circ}$ Solución del problema de la salubridad bajo inspiración de que el Estado debe protección preventiva y curativa a la salud física y mental de sus miembros, (...), $19^{\circ}$ Organización por el Estado de la asistencia social para los niños y madres desvalidos (...), $22^{\circ}$ Educación como función exclusiva del Estado y supresión, por lo tanto de la enseñanza congregacionista, escuela única: gratuidad de la enseñanza y del material escolar (...), $23^{\circ}$ Reforma universitaria con participación del estudiantado (...), 31 $1^{\circ}$ Revisión de la legislación relacionada con la raza indígena en forma que consulte un efectivo respeto a sus derechos y mejoramiento de sus condiciones de vida, trabajo y cultura" (Frente Popular en La Opinión; 1936, p. 12).

Como vemos, es un programa que además de parecer un listado de peticiones, permite interpretar que la preocupación del Frente Popular por justicia social se relaciona con recursos o bienes que se deben poseer por igual entre la población y especialmente aquellos a quienes se les han negado y participan de situaciones de desventaja al interior de la sociedad -trabajadores/obreros, clases medias, mujeres, niños y etnias-, lo cual es sumado a otorgar libertades básicas de asociación, voto y derechos. Respecto de los bienes primarios, identifican el salario/renta, la educación, la asistencia social para grupos prioritarios como mujeres, niños y la salud independientemente del sexo, la educación única planteada, se basa en una escuela laica, capaz de entregar las herramientas para el desarrollo de cada sujeto. Por otro lado, las libertades básicas con las que se debe contar en la sociedad chilena de ese tiempo, refieren a la libertad política y el reconocimiento de la pluralidad, lo cual implica reconocer la necesidad de ciertas estructuras institucionales que las soporten y en eso su apelación a permitir que la legislación del país incorpore la huelga o la asociación es algo clave, así como la participación de los sujetos en instancias estudiantiles y la libre expresión a través de los mecanismos existentes para ello. Una sociedad justa necesitaría de un sistema de protección de los recursos naturales e industrialización por parte del Estado, es decir, de un Estado que debe tener una participación mayor en esas áreas, mayor control y dirección, pero respetando el horizonte capitalista.

El acuerdo del Frente y de su Programa no implica que no sea un período de colaboración crítica entre las diversas organizaciones políticas, la cual finalizará con fuertes disensiones entre el PC y el PS, llevando al rompimiento en las relaciones entre éstos y entre ellos y el Partido Radical ${ }^{24}$, poniendo fin al Frente Popular. Incluso el PS sufre una gran crisis interna entre la corriente de los oponentes a la creación del Frente Popular y la que es favorable a ella, generándose una división en el partido en 1939, donde la oposición interna se retira y crea el Partido Socialista de los Trabajadores que más tarde pasará a ingresar las filas del PC.

A partir de 1941 el PC tenía a su haber la emergencia de un sentimiento anticomunista especialmente por parte del PS, sentimiento que los socialistas explicaban en función de lo que consideraban el carácter satélite del PC chileno respecto de la III Internacional,

${ }^{24}$ El Partido Radical -como partido de centro- igualmente presentaba corrientes en su interior divididas en un ala más derechista y una pro comunista/socialista. 
combinado con la necesidad y disputa de representar a los sectores populares y de la clase obrera. Esa calificación por parte del PS, se ratificaba en que el PC chileno a partir de 1941 pasa a funcionar con la lógica de la Unidad Nacional -que es la política desarrollada por los partidos comunistas durante el desarrollo de la Segunda Guerra Mundial- cuyo programa sintoniza con la lucha contra el nazifascismo y la llamada a todos los partidos y organizaciones populares a fin de "impedir el golpe de Estado fascista y prestar ayuda a los pueblos que luchan contra el fascismo".

La lucha de masas es una nueva etapa en el accionar del PC chileno, comenzando en 1945 y finalizando en 1951 con la expulsión del reinosismo ${ }^{25}$ de sus filas. Coincide con una fase de participación en el gobierno de Gabriel González Videla y una segunda fase de aislamiento y la ilegalidad del PC en el plano nacional ${ }^{26}$, lo que se conjuga con la agudización de la Guerra Fría y las democracias populares en el nivel internacional. El PS, por su lado dividido, en 1946 da inicio a la política del Tercer Frente -impulsado por el Partido Socialista Auténtico- que significaba dar continuidad al Frente Popular y a la alianza Democrática. Sin embargo, seguirá caracterizándose por su fuerte anticomunismo.

Frente a ello, el PC comienza a apelar a la unidad en la base en organizaciones que hasta ese entonces no habían sido considerados interlocutores frente al Estado. Y después del rompimiento de las relaciones entre socialistas y comunistas, será en el terreno reivindicativo, a través de las luchas gremiales y sindicales que se construirán nuevamente acciones comunes entre estos militantes que a partir de los años 50 permitirá forjar el Frente del Pueblo (1951-1955) ${ }^{27}$.

Recordemos que entre los años 1948 y 1958 se aplicó sobre el PC la ley de Defensa Permanente de la Democracia, que excluía al partido del sistema político chileno,

${ }^{25}$ El reinosismo se entiende referido a Luis Reinoso, secretario de la organización del PC de Chile a fines de los años 40. Inaugura una forma determinada de actuar y que tuvo su origen y expresión entre los años 1948 y 1951, durante la plena vigencia de la ley de Defensa Permanente de la Democracia. Su énfasis estuvo puesto en favorecer la acción revolucionaria directa, por medio de lucha frontal y violenta, todo lo cual llevó a la expulsión de los seguidores de esta vertiente por considerarlos una "desviación de izquierda". Esta forma de entender la acción que debía tener el PC, se debió a que Reinoso constata en Chile que la debilidad de la democracia burguesa no permite el tránsito hacia la sociedad socialista por medio de la profundización democrática bloqueada por el poder que mantenía la oligarquía terrateniente. Ver detalles en Loyola, Manuel: "Los destructores del Partido": notas sobre el reinosismo en el Partido Comunista de Chile. Revista Izquierdas, año 1, $\mathrm{N}^{\mathrm{o}}$ 2. Disponible en http://www.izquierdas.cl/html/numero_2/Reinosismo.pdf. Revisada el 12 de abril de 2009. ${ }^{26}$ Eduardo Devés llama la atención acerca de que después de la II Guerra Mundial, se produce en Chile una oleada modernizadora "que asume la forma ideológica del desarrollismo que postula ideas de industrialización y sustitución de importaciones. Sociólogos y economistas formulan una nueva versión del proyecto modernizador, del crecimiento hacia adentro" (Devés, E., 1999, p. 215).

${ }^{27}$ Es interesante enfatizar que en el trasfondo de todas estas disputas, alianzas y diferencias, en el plano de las ideas existentes en el ambiente de esos años y que influyeron también a la izquierda, se encuentran según Eduardo Devés (2003) las ideas sobre el desarrollo de Raúl Prebisch propia de los años 50 y que serán rastreadas posteriormente en el planteamiento de la Cepal. El concepto de desarrollo y subdesarrollo, junto con la relación centro/periferia para entender la vinculación a nivel mundial, como también industrialización, pasan a ser incorporados en el bagaje intelectual latinoamericano y por supuesto chileno, a partir de la segunda mitad del siglo XX de la mano de la escuela de la Cepal. Este mismo autor, muestra que en muy poco tiempo las ideas de la Cepal -creada en 1948-influyeron en organismos públicos a nivel latinoamericano, el tema del desarrollo y la propuesta modernizadora-industrializadora como también los conceptos de periferia, dependencia, marginalidad.

Por otro lado, en el ámbito del desarrollo literario, nos encontramos con la generación del 38 ya anunciada anteriormente, donde la obra tendrá relación y compromiso con los temas sociales. Así también notamos en este período en la obra de Pablo Neruda su intromisión y toma de posición en el espacio político, después de su vivencia de la Guerra Civil Española. Obras como Canto General (1950) o los Versos del Capitán (1952) muestran una poesía que adopta un sentido político, social, ético y americano, la poesía se hace compromiso político. 
permitiendo perseguir y encarcelar a centenares de militantes y dirigentes. Ley a la que se opuso claramente una parte del PS, a pesar de su posición ideológicamente contraria al PC. Este punto generó una nueva división al interior del PS, conformándose el Partido Socialista de Chile -de una marcada tendencia anticomunista- y el Partido Socialista Popular -que defendía el derecho de los comunistas a participar en la vida política- en el que se ubicó Salvador Allende.

Durante este período, 1951, desde la clandestinidad, el PC chileno planteó el Programa de Emergencia Nacional publicado bajo el título "La lucha por la paz es la lucha por el pan, la libertad y la independencia nacional" 28 -y que será base de los contenidos definidos del Proyecto del Frente de Liberación Nacional que será la línea estratégica con que el PC entenderá el Frente de Acción Popular (FRAP) creado en 1956 y que se distinguirá del entendimiento que hará de esto el PS, quien lo interpretará como el Frente de Trabajadores ${ }^{29}$.

El Partido Socialista Popular (PSP) en 1950 proclamó la candidatura de Ibañez -candidato de la derecha en 1942- que llevó a Allende junto a otros militantes a renunciar y a fusionarse con el Partido Socialista de Chile. El PSCH en 1951 proclama a Salvador Allende como candidato a la presidencia. Con la perspectiva de una política de alianzas, desde la clandestinidad, el PC decidió apoyar la candidatura de Allende para las elecciones de 1952. Con ello, se intentaba re-editar la experiencia del Frente Popular, pero conducido por las organizaciones de la clase trabajadora. Para ello, el PC se alió al Partido Socialista de Chile en el Frente del Pueblo que impulsaba un programa de cambios antioligárquico, antifeudal y antiimperialistas.

Allende definía el Frente del Pueblo del siguiente modo:

"Somos un movimiento de liberación nacional, anti-imperialista, anti-oligárquico, con una meta que no termina en septiembre. Estamos protagonizando una gesta emancipadora por el pan y la libertad, por el trabajo y la salud, por la reforma agraria y la industrialización del país, por la paz, la democracia y la independencia nacional".

\footnotetext{
${ }^{28}$ Este programa de Emergencia, cuya base se encontrará en los programas sucesivos, visualizamos una noción de justicia social, enunciada de la siguiente forma:

" $1^{\circ}$ Defensa económica de los trabajadores: Reajuste de sueldos y salarios según costo de la vida; garantía de trabajo para todos los chilenos de la cesantía y de las discriminaciones políticas; perfeccionamiento de la Previsión Social; para el problema habitacional, hacer uso de los terrenos fiscales, Cajas de Previsión y dar cumplimiento a la ley económica (...) $2^{\circ}$ Defensa de la economía nacional (...) asegurar maquinarias, materias primas y crédito adecuado a la industria chilena, suspensión del pago de la deuda externa mientras dure la crisis (...)

$4^{\circ}$ Restablecimiento de las libertades democráticas: Derogación de la ley de Defensa Permanente de la Democracia, de la Ley de Seguridad Interior del Estado y de la ley de sindicación de asalariados agrícolas. Disolución de la Policía Política y castigo para los flageladores.

$5^{\circ}$ Por el abastecimiento alimenticio del país: obligatoriedad del cultivo de tierras inexploradas; créditos, abonos, maquinaria y asistencia técnica para aumentar la producción agrícola; requisamiento por el período de crisis de las tierras inexploradas. Entrega en arriendo o gratuitamente al campesino que las quiera trabajar; parcelación de tierras fiscales y entrega de éstas a chilenos que quieran trabajarlas; devolución de tierras a mapuches y títulos de dominio a ocupantes de tierras fiscales (...)" (Programa de Emergencia del PC chileno. En Gómez, María Soledad; 1988, pp. 128-129).

${ }^{29}$ Las diferencias de la política del Frente de Trabajadores respecto de la del Frente de Liberación Nacional se basan en que los primeros la entienden como una táctica de lucha de la clase obrera y las nuevas circunstancias nacionales y mundiales, por la conquista del poder político. Agrupa a las masas por su carácter de clases explotadas con el fin de enfrentar a la clase capitalista, la pugna es entonces entre el proletariado y la burguesía. Así, el Frente de Trabajadores no distingue en las filas de la burguesía un sector progresista que si es identificado por el Frente de Liberación Nacional llevado por los comunistas y que impulsaban el desarrollo de una revolución burguesa. Las diferencias ideológicas entre socialistas y comunistas no impiden en que se trace entre ambos una unidad y con ello, la unidad del movimiento popular.
} 
La plataforma -a través del Programa- representaba una instancia para unir fuerzas de diverso tipo "en un amplio movimiento de liberación nacional y social (que) abarque a la mayoría de los chilenos y que consolide y desarrolle al calor de las luchas reivindicativas de los obreros, de los empleados, de los campesinos, de los profesionales, intelectuales, estudiantes, jóvenes, mujeres, pequeños comerciantes e industriales, en una palabra, todas las capas sociales y populares y progresistas del país"(Daire, Alonso; 1988, p. 151).

Las bases programáticas se dividían en cuatro puntos:

1. Independencia económica y comercio exterior con la nacionalización de la minería del cobre y del salitre

2. Desarrollo de la economía interna, bajo la industrialización e inversiones en el transporte

3. Profunda reforma agraria

4. Mejora de las condiciones de vida de las clases populares

El programa del Frente del Pueblo no buscaba la construcción de una sociedad socialista, sino "un conjunto de reformas y modernizaciones que pretendían ir más allá de lo logrado por Pedro Aguirre Cerda, con un énfasis novedoso en la reforma agraria y el cobre" (Amorós, M., 2008).

Alonso Daire (1988), nos hace ver acerca de la influencia que ejerce la propuesta elaborada por el PC -a través de la formulación que hace en el Programa del Frente Nacional de Liberación- y que será finalmente la que a grandes rasgos se incluirá en el Frente de Acción Popular. Algunos de los elementos presentes en el Programa del Frente Nacional de Liberación son:

“1) Organización de todo el pueblo trabajador del campo y de la ciudad para llevar a cabo la unidad nacional del movimiento obrero. 2) Solución al problema agrario, expropiando el latifundio y distribuyendo la tierra a los campesinos, que pagarían por ella. 3) Lucha por la nacionalización de las industrias que estaban en manos de compañías extranjeras y fin del imperialismo en Chile. 4) Democratización del Estado y del sistema político. 5) Lucha organizada por la línea de independencia nacional. 6) Y la realización de todo el Programa por medios pacíficos (...) Destaca como línea oficializada la vía pacífica y las formas de lucha que ella implica."(Daire, Alonso; ídem, pp. 159-160) ${ }^{30}$.

A partir de 1956 se crea la alianza política llamada Frente de Acción Popular (FRAP), integrado por el PC, PS, Partido Democrático, Partido del Trabajo, Partido del Pueblo, Partido Radical Doctrinario, Alianza Nacional de Trabajadores y el IRA. Así también, la unidad sindical -en la Central Unitaria de Trabajadores de 1953- fue fundamental

\footnotetext{
${ }^{30}$ Respecto de la vía pacífica seguida por el PC chileno, es la vía chilena al socialismo, táctica que no se abandonará hasta conseguir el gobierno de Allende. Luis Corvalán la define como aquella "no debe ser identificada con la senda de una elección parlamentaria, ni con el camino de una elección presidencial, aunque es de toda evidencia que ambas alternativas caben dentro de ella. Lo importante es comprender que en el ámbito de la vía pacífica caben diversas situaciones que se pueden producir y variadas formas de lucha de las masas, incluso formas agudas de la lucha de clases, como la huelga general, excluyendo solamente el empleo de la violencia en forma de guerra civil o de insurrección armada de todo el pueblo" (Luis Corvalán en Daire; ídem, p. 184).
} 
para la construcción del FRAP y de la unidad de la izquierda ya que tanto el PC como el PS tenían diferencias de apreciación acerca de la alianza política con la burguesía y de la burguesía nacional y respecto del centro político chileno (Daire, 1988; Benavides, 1988, Moulian, 2006). A pesar de la alianza en el FRAP, las diferencias se mantuvieron entre ambos partidos, no así la división del PS, ya que en 1957 logra la unidad de los partidos socialistas de Chile y Popular.

El Frente de Acción Popular se plantea como "una organización política unitaria (...) se caracterizará, fundamentalmente, por ser el núcleo aglutinador de las fuerzas que estén dispuestas a luchar por un programa antioligárquico, antimperialista y antifeudal. Su acción esencial se dirigirá a consolidar un amplio movimiento de masas, que pueda servir de base social a un nuevo régimen político, inspirando en el respeto de los derechos y aspiraciones de la clase trabajadora y dirigido a la emancipación del país, al desarrollo industrial, a la eliminación de las formas feudales de la explotación agraria, al perfeccionamiento de las instituciones democráticas, a la planificación del sistema productivo con vistas al interés de la colectividad y a la satisfacción de las necesidades básicas de la población trabajadora.

En su acción inmediata, el Frap luchará infatigablemente por la defensa de las libertades públicas y sindicales; por la derogación de las leyes represivas y el Estado de sitio, por la defensa de las conquistas, los derechos y las organizaciones de la clase trabajadora y especialmente, por la unidad, el fortalecimiento y la legalidad de la Central Unitaria de Trabajadores; contra la política antipopular del gobierno y la represión desencadenada contra las organizaciones sindicales y política, contra la penetración imperialista y para impedir la consumación de atentados contra el interés nacional, expuestos en la concesión de irritantes privilegios al capital foráneo, tales como la ley que concedió nuevo trato al cobre y el referéndum salitrero" (FRAP en el Siglo; 1956, p. 9).

A partir de esta declaración podemos interpretar que la noción de justicia social se entrelaza con lo que ya mencionamos anteriormente en la dialéctica entre necesidad y libertad, lo cual implica distribuir bienes primarios como derechos, necesidades básicas y libertades especialmente para aquel sector de la sociedad que no goza de aquello, como es la clase trabajadora. Igualdad y libertad son los ejes de esta noción, pero adquiriendo matices propios de las discusiones y debates del período en que se gesta el FRAP. La libertad, como dimensión inmaterial se concreta en la declaración del respeto por los derechos, las libertades públicas y sindicales, el perfeccionamiento de las instituciones democráticas y también la derogación de leyes represivas. La igualdad debe ser capaz de sostener lo anterior, posible a través del desarrollo industrial del país, eliminando las formas feudales de explotación agraria y la satisfacción de las necesidades básicas de la población trabajadora. En ese sentido, se deja ver una suerte de igualdad y prioridad por los que se ubican en una posición desventajosa en la sociedad y que las propias estructuras sociales tienen mucha responsabilidad. Justicia social entonces implica libertad e igualdad y una sin la otra parece que no son posibles. No es claro que para ello el FRAP precise declararse anticapitalista como si lo hará la Unidad Popular, aspecto que llama la atención en tanto subyace una idea 
donde el Estado asume una función fundamental en la transformación social y el control del capitalismo (aspecto presente en Rawls).

Como es sabido, a partir de 1958, con la legalidad obtenida para el PC a través de la derogación de la "Ley Maldita" o de defensa de la democracia, se levanta nuevamente la candidatura de Salvador Allende por parte del Frente de Acción Popular, obteniendo un gran apoyo del mundo popular, pero aún insuficiente para que obtuviera la presidencia.

Asimismo, el FRAP volvió a fracasar para las elecciones de 1964, triunfando la Democracia Cristiana y con ello, provocando un cuestionamiento al interior de la izquierda chilena. De tales cuestionamientos al interior de la izquierda y de los procesos e influencias internacionales surge una tendencia ultraizquierdista que será alimentada por grupos de estudiantes e intelectuales provenientes del PC y del PS que se inclinan por defender la lucha armada como único medio para obtener el poder para la clase trabajadora. Se da paso a la formación del MIR en 1965.

\section{Declinación del FRAP y emergencia de la Unidad Popular (UP): más allá de la izquierda PC-PS, 1960-1970.}

Según Eduardo Devés (1999), en los años cincuenta el pensamiento marxista se caracterizó por la adopción del leninismo, la idea de revolución, el deseo de interpretar la realidad específica, el afán de "aplicar" las tesis del marxismo a la economía y a la política en Chile. Todo lo cual ya a mediados de los años sesenta irrumpió en un nuevo grupo de marxistas con dimensiones que se combinaron con las anteriores. Se sumaron el tercermundismo y la categoría "dependencia", una herencia guerrillera, guevarista y un carácter latinoamericanista.

Lo anterior se engarza a los procesos sociales vividos por gran parte de la sociedad chilena, junto a algunos hitos latinoamericanos. Podemos decir, que el proceso político y social en Chile mostraba que entre los años 58 y 64 el gobierno de Jorge Alessandri -Presidente de la República representante de conservadores y liberalesrealizó acciones que afectaron negativamente a los sectores populares ${ }^{31}$, generando las condiciones para amplias movilizaciones populares de protesta a partir de los años sesenta. Se suma a ello, que hechos políticos internacionales como la Revolución Cubana, la experiencia de la lucha guerrillera en América Latina y las consecuencias de la disputa chino/soviética con la crisis y la división del movimiento comunista internacional influirán en toda una generación de jóvenes. Para los primeros años de la década del sesenta existían diversas organizaciones y agrupaciones que se habían formado o escindido de la izquierda tradicional y que tenían un sentido crítico con

\footnotetext{
${ }^{31}$ Algunas de las medidas económicas que impulsó fue la racionalización de los gastos del sector público, el congelamiento de los sueldos y salarios, favoreció el ingreso de productos e inversión extranjera, todo en el contexto de cumplir con las exigencias de la Alianza para el Progreso.
} 
la vía asumida por el FRAP ${ }^{32}$, todo lo cual permitió la emergencia del Movimiento de Izquierda Revolucionaria -MIR- en 1965.

El paso -a fines de los años sesenta- desde el FRAP hacia la UP no hace que se aminoren ni olviden las diferencias existentes entre el PS y PC. Para algunos autores, la Unidad Popular fue una realización de la práctica y pensamiento comunista, en cuanto incorpora sectores de la Democracia Cristiana, el Partido Radical, el Movimiento de Acción Popular Unitaria (MAPU), donde la unidad de clase no era el hilo que las definía, al contrario de lo planteado por el PS que sostuvo la necesidad de alianza con orientación clasista. Así también, la vía pacífica fue la política oficial de la UP a diferencia de la vía armada como forma de lucha para Chile, pregonada por el PS.

A mediados de los sesenta ya se podía observar al interior del mundo de la izquierda, dos referencias, una ligada al FRAP y que luego pasaría a llamarse Unidad Popular (UP) y uno ligado a grupos convencidos de que la lucha parlamentaria y electoral había fracasado y que se debía destruir la legalidad burguesa a través de métodos de lucha revolucionarios para alcanzar los objetivos clasistas y populares.

En 1969 fue aceptado el Programa de la Unidad Popular, la que fue compuesta por el PC, PS, P. Radical, el Movimiento de Acción Popular Unitaria y Acción Popular Independiente. Entre los insumos de que se nutrió el Programa de la UP y Allende fueron los estudios realizados y diagnósticos económicos sobre la situación chilena y propuestas programáticas que algunos personeros del PC venían trabajando desde 1956 y que asumían la influencia -sin el sentido de copiar para la realidad chilena- del proceso de la URSS, China, Cuba y Europa Oriental, como también las visiones de Keynes, Prebish y la Cepal ${ }^{33}$.

\footnotetext{
${ }^{32}$ Luis Vitale (1999), Naranjo et al. (2004) mencionan que para el año 1962 en Chile se había formado la Vanguardia Revolucionaria Marxista (VRM), en que confluían sectores escindidos del PC, el grupo Movimiento de Resistencia Antiimperialista de Luis Reinoso y Martín Salas, el Movimiento 2 de Abril, de antiguos sectores trotskistas separados del PC en 1938. El Partido Revolucionario Trotskista y Movimiento Revolucionario Comunista escindido de las Juventudes Comunistas. Además surgió el Movimiento de Fuerzas Revolucionarias en 1961 integrado especialmente por obreros sindicalizados, el Partido Obrero Revolucionario. Ya en 1964 se integran a VRM, Miguel Henríquez, Bautista van Schouwen expulsados o renunciados del Partido Socialista. Todas estas organizaciones se autodisuelven para constituir un solo partido, el MIR, lo cual da cuenta de que previo a su inicio cronológico existe un desarrollo, práctica política y reagrupamientos de diversos grupos políticos.

${ }^{33}$ En una entrevista realizada a José Cademártori, militante del PC a partir del año 1954 y posteriormente miembro del Comité Central en 1958, podemos observar el reconocimiento de influencias teóricas y políticas como las mencionadas: “¿Cuáles fueron sus primeras labores como militante comunista? Respuesta: Las primeras labores fueron todas relacionadas con asesorías en mi materia, públicamente no podía hacer nada. Eran opiniones sobre distintos temas, en documentos. 1956 fue el año en que se hizo el X congreso del PC, clandestino. Para ese congreso se me requirió, al igual que a los otros integrantes de la célula, aportes como diagnóstico de la situación chilena y propuestas programáticas. Creo que eso tuvo su importancia porque esos estudios constituyeron una de las primeras vertientes desde donde surgió el programa de Allende y de la Unidad Popular. Los que trabajábamos ese tema, más otros que se sumaron en años posteriores, discutíamos sobre una vía chilena para el socialismo, particularmente en el plano económico. Tuvo esa concepción sin embargo, un vacío, y es que se desarrolló poco la estrategia política y de seguridad, faltaban especialistas. Sin pensar en copiar nada, sino partiendo de la realidad y la historia de Chile, asimilamos la experiencia de la URSS, los países de Europa Oriental, Cuba y China; las visiones de Prebish y la CEPAL, los aportes de Keynes, de otros pensadores progresistas, de Baran y Lange y las teorías de Keynes. Surgía otro grupo vinculado a Allende. Teníamos contactos con Gonzalo Martner, Max Nolf, Pedro Vuskovic, Carlos Matus y otros más con quienes compartíamos algunas ideas. Éramos un equipo asesor informal, aunque para las campañas presidenciales se formalizó con muchos otros profesionales como abogados, médicos y arquitectos". Moyano, Cristina; La Trayectoria de un economista comunista: del FRAP al triunfo del NO. Enero de 2009. Ver entrevista completa a José Cademártori, último ministro de economía del presidente Allende, en http://www.rebelion. org/noticia.php?id=79520. Revisado el 20 de marzo de 2009.
} 
En ese sentido, en los años sesenta surge una corriente crítica para analizar la particularidad de América Latina, la Teoría de la Dependencia que recibiendo la influencia del cepalismo, las teorías de la modernización, con la teoría del imperialismo y las del nacionalismo económico latinoamericano, se constituye en una escuela crítica de esas tendencias, especialmente las teorías del desarrollo de la Cepal ${ }^{34}$.

Es sabido que varios de los exponentes teóricos extranjeros de esta tendencia como Ruy Mauro Marini, Theotonio dos Santos, Vania Bambirra, André Gunder Frank, y su contraparte chilena como Orlando Caputo, entre otros, también fueron militantes o simpatizantes de partidos y movimientos de la izquierda chilena de la época. En ese sentido, esta teoría no solo adquirió una importancia teórica sino también influyó políticamente. Vania Bambirra reconoce que la teoría de la dependencia fue muy bien recepcionada en el Partido Comunista chileno e influyó en el programa de gobierno de la Unidad Popular ${ }^{35}$, como en el Movimiento de Izquierda Revolucionaria (MIR) chileno.

El Programa de la Unidad Popular diagnostica que Chile es un país capitalista, dependiente del imperialismo, dominado por sectores de la burguesía estructuralmente ligados al capital extranjero, en el que la burguesía monopolista nacional crecientemente asume un papel de dependencia como socio menor del capital extranjero. Parte de la base que las recetas "reformistas" y desarrollistas, impulsadas por la Alianza para el Progreso no alteraron el estancamiento económico, la carestía y la represión violenta contra el pueblo (Programa Unidad Popular, 1969).

El Programa de la Unidad Popular incluye la nacionalización de las riquezas básicas: cobre, hierro, salitre y el carbón, la banca financiera del país, el comercio exterior, las grandes empresas y monopolios de distribución; los monopolios industriales estratégicos; energía eléctrica, transporte aéreo, ferroviario y marítimo; las comunicaciones; producción, refinamiento y distribución de petróleo etc. Además plantea profundizar y extender la Reforma Agraria. En lo que a las tareas sociales menciona:

\footnotetext{
${ }^{34}$ En ningún caso se puede desconocer la tradición marxista a la que se adscribe la teoría de la dependencia, Vania Bambirra es clara en este punto al mencionar "Son pues sus antecedentes teóricos y políticos los análisis de Marx y Engels sobre la situación colonial; la polémica de los socialdemócratas rusos y de Lenin en particular en contra de los narodniki-populistas; la teoría del imperialismo y sus alcances en la situación colonial elaborada por Hilferding, Bujarin, Rosa Luxemburgo y particularmente por Lenin; la polémica sobre la revolución colonial llevada a cabo en el II Congreso de la Comintern que culmina con la elaboración de las tesis sobre las cuestiones nacional y colonial por Lenin; las consideraciones posteriores hechas por Lenin mismo, de carácter disperso pero de todos modos muy significativas; la aplicación creadora del marxismo-leninismo expuesta por Mao Tse-tung en varias de sus obras; y, finalmente, el intento de aplicación del método de análisis marxista para la comprensión del fenómeno del "subdesarrollo" realizado por Paul Baran en los años cincuenta" (Bambirra, V., 1978, p. 4).

${ }^{35}$ Vania Bambirra, expresa del siguiente modo la relación entre la Teoría de la Dependencia y el Programa de la Unidad Popular, "El programa de la UP contemplaba como meta no sólo terminar con la dominación oligárquica imperialista, sino que planteaba explícitamente nacionalizar las grandes empresas monopólicas industriales, mineras, agrícolas, etcétera, vale decir, golpear el eje básico de la dominación burguesa-imperialista y avanzar hacia el socialismo. De esta manera, la UP trataba en la práctica de implementar la concepción que había sido demostrada por la revolución cubana y confirmada por las investigaciones teóricas y empíricas respecto del capitalismo dependiente: que el imperialismo era un elemento constitutivo interno del sistema de dominación y que para llevar a cabo una política consecuente de liberación nacional y social había que rebasarlo, avanzando hacia el socialismo" (Bambirra, V., 1978, p. 8). En entrevista realizada a Teothonio do Santos (2009), éste supone que la influencia de la Teoría de la Dependencia hacia el PC y la UP, se realiza a través de militantes comunistas (y a la vez) economistas chilenos como Orlando Caputo que conforman un grupo de estudios junto a Teothonio do Santos (en la época militante del PS), Vania Bambirra y otros. Y la influencia de la teoría en el MIR es a través de Ruy Mauro Marini, uno de sus militantes.
} 
a) Definición de una política de remuneraciones (...) b) Unificar, mejorar y extender el sistema de seguridad social, manteniendo todas las conquistas alcanzadas, eliminando los privilegios abusivos, la ineficacia y el burocratismo, mejorando y haciendo expedita la atención de los interesados, extendiendo el sistema previsional a los sectores de trabajadores que aun no lo tienen (...) c) Asegurar la atención médica y dental preventiva y curativa a todos los chilenos, financiada por el Estado, los patrones y las instituciones de previsión (...) d) Se destinarán fondos suficientes a fin de llevar a cabo un amplio plan de edificación de viviendas (...) Llevar adelante la remodelación de ciudades y barrios, con el criterio de impedir el lanzamiento de los grupos modestos a la periferia, garantizando los intereses del habitante del sector remodelado, como del pequeño empresario que allí labore, asegurando a los ocupantes su ubicación futura. e) Se establecerá la plena capacidad civil de la mujer casada y la igual conducción jurídica de todos los hijos habidos dentro o fuera del matrimonio así como una adecuada legislación de divorcio con disolución de vínculo, con pleno resguardo de los derechos de la mujer y de los hijos (...) El nuevo Estado procurará la incorporación de las masas a la actividad intelectual y artística, tanto a través de un sistema educacional radicalmente transformado, como a través de un sistema nacional de cultura popular. El sistema de cultura popular estimulará la creación artística y literaria y publicará los canales de relación entre artistas o escritores con un público infinitamente más vasto que el actual.(...)

El Gobierno Popular garantizará el ejercicio de los derechos democráticos y respetará las garantías individuales y sociales de todo el pueblo. La libertad de conciencia, de palabra, de prensa y de reunión, la inviolabilidad del domicilio y los derechos de sindicalización (...) el Gobierno de la Unidad Popular garantizará el derecho de los trabajadores al pleno empleo y a la huelga y de todo el pueblo a la educación y a la cultura, con pleno respeto a todas las ideas y de las creencias religiosas, garantizando el ejercicio de su culto. (Programa de la Unidad Popular, 1969).

Como vemos esta lista de tareas sociales dejan entrever las dimensiones que apuntan a igualar las condiciones materiales en las que viven los trabajadores, a través de extender el sistema previsional y de seguridad social, asegurando también la atención médica y dental, la edificación de viviendas, remodelación de barrios y ciudades, el derecho al empleo. A la vez, la dimensión de la libertad se materializa en el acceso de las masas a la actividad intelectual, artística, cultural y literaria, además del respeto por las garantías individuales y sociales del pueblo, de la libertad de conciencia, creencias religiosas, de palabra, prensa, reunión y sindicalización. Ambas dimensiones vemos que están íntimamente ligadas y se complementan. La interpretación que podemos hacer de la noción de justicia social es que esta no se reduce a igualar condiciones económicas-sociales y políticas a través de la obtención de bienes primarios, para la clase trabajadora y el pueblo (que siempre había sufrido privaciones), sino a incorporar la igualdad unida a la libertad que respeta derechos, conciencia y credo. Sin esa relación difícilmente se podría pensar esa sociedad como una sociedad con justicia social. Pero debemos llamar la atención que la igualdad propuesta es radical en la medida que la UP se pronuncia por un sistema anticapitalista, en ese sentido, reconoce que no es posible realizar aquello bajo un sistema capitalista. Sin embargo, definir que la manera de llegar a ello, era dentro del sistema constitucional, por lo tanto, en función de las reglas del juego del sistema capitalista imperante en Chile hasta ese momento, fue un error imposible de olvidar. 
Un análisis propio amerita el Programa del Movimiento de Izquierda Revolucionaria -MIR- debido a que surge dentro del espectro de la izquierda tradicional, pero diferenciándose de ella. Creemos que revisar su propuesta programática nos permitirá establecer sintonías y disonancias con la propuesta de la UP, independientemente de que el contexto explique el distanciamiento entre ambas orgánicas. Fijamos la mirada en el MIR porque pertenece a la tradición marxista como se definió también el PC y el PS.

El MIR se define como una organización marxista-leninista que se rige por el centralismo democrático. Siguiendo a Naranjo et al. (2004) entre 1965 y 1967 la organización está marcada por la diversidad de grupos, fracciones y disputas en su interior que lo llevan a tener niveles orgánicos mínimos, como también la incapacidad de generar una estrategia y táctica definida y una vinculación con las masas. A partir de 1967 asume el Comité Central Miguel Enríquez junto a otros compañeros provenientes de la Universidad de Concepción, y es a partir de esa fecha que aumenta el número de militantes, se crece en diversas zonas del país y se gana influencia en algunos frentes de masas. En 1969 se produce una separación de la organización yéndose entre un $15 \%$ y un $20 \%$ de la capacidad partidaria especialmente por las diferencias existentes al interior de ésta. Sin embargo, a partir de ese momento se propone un modelo orgánico para una nueva organización que permitió comenzar acciones armadas junto con la inserción en los frentes de masas, homogeneizándose políticamente como organización.

La caracterización que hicieron de la sociedad chilena en la época es que "no existen resabios feudales ni revoluciones burguesas antifeudales y antioligárquicas por hacerse, ni se puede esperar que los éxitos macroeconómicos terminen, por "chorreo", mejorando sustantivamente las condiciones de vida del pueblo. La miseria de las masas no es producto de un déficit de desarrollo capitalista sino el resultado propio de ese desarrollo. Lo que existe es el "desarrollo subdesarrollado" (Naranjo et al., 2004, p. 17). Esta caracterización se basa en la influencia de la Teoría de la Dependencia que varios de sus militantes y simpatizantes abrazaban en la época. La dependencia hace que la situación del proletariado también se modifique, en función de la definición clásica asimilable al sector obrero industrial. Para ellos, este sector se conforma también por capas medias proletarizadas y el semi y subproletariado que producen plusvalía. Para el MIR no había sectores del pueblo que podían progresar en forma sustantiva con la profundización del desarrollo capitalista, por lo que se tornaba relevante terminar con el capitalismo.

Con esta evaluación de la situación del capitalismo en Chile y América Latina, el MIR rechaza el postulado presentado en diversos momentos por la izquierda tradicional; "de una revolución democrática, nacional y popular en alianza con sectores burgueses, que en términos concretos era levantada para Chile como antiimperialista, antioligárquica y antimonopólica"(Naranjo et al., 2004, p. 17).

El MIR no fue parte de la Unidad Popular, debido a que no creyó que la transición hacia el socialismo podría hacerse por vía pacífica. Sin embargo, en la coyuntura electoral 
de 1970 cambiaron la percepción de que la izquierda sería derrotada, al evaluar que las "clases dominantes" iban divididas a la elección, situación que los llevó a otorgar su apoyo crítico a la UP, en función de defender las conquistas alcanzadas por el pueblo.

Algunos elementos de su Programa planteaban lo siguiente:

“Nuestro país semi-colonial, tanto por su estructura económica como por su dependencia del mercado mundial, necesita enfrentar tareas básicas: la liquidación del imperialismo y la revolución agraria. Tras estas medidas debe movilizarse a la mayoría nacional compuesta por obreros, campesinos y sectores medios empobrecidos.

1.- La expulsión del imperialismo significa:

a) Nacionalización, sin indemnización, de las empresas del cobre, salitre, hierro, electricidad, teléfonos (...) y de los bancos extranjeros.

b) Ruptura de los pactos que nos atan al imperialismo y afectan a nuestra soberanía nacional, como el Tratado Militar con EE.UU., la OEA, el Fondo Monetario Internacional y otros.

c) Desconocimiento de la deuda externa contraída por los gobiernos burgueses con el imperialismo (...)

2.- La revolución agraria significa:

a) Expropiación, sin indemnización, de las tierras en poder de los latifundistas, y su entrega a los camerinos que las trabajan, entrega que podrá ser individual o colectiva de acuerdo a las condiciones específicas de cada zona, e irá acompañada de ayuda técnica, de créditos, maquinarias, semillas y demás medidas encaminadas a elevar el nivel de la productividad del agro

b) la revolución agraria debe concretarse en la ocupación de tierras por los campesinos (...) La lucha por esos objetivos revolucionarios no excluye la movilización de las masas por reivindicaciones inmediatas, como ser: Reajuste móvil de sueldos y salarios, asignación familiar móvil e igualitaria, contratos colectivos, sindicatos únicos por industria, control obrero de la producción, disminución progresiva del impuesto directo, jornada de 40 horas de trabajo, libertad de sindicalización por campesinos y para los obreros y empleados fiscales y municipales, ampliación del derecho a voto de los analfabetos y mayores de 18 años, como también de suboficiales y tropa, educación obligatoria y gratuita, etc.

Movilizaremos a los trabajadores aplicando los métodos de la lucha de clases, como la huelga, la ocupación de tierras, fábricas y terrenos, los grupos de autodefensa, etc. La lucha por las reivindicaciones inmediatas no debe transformarse en una meta final, como lo plantean los reformistas, sino que debe servir para elevar a un plano político revolucionario a las masas que se movilizan por tales objetivos concretos.

El MIR sostiene que el programa planteado solo podrá realizarse derrocando a la burguesía e instaurando un gobierno revolucionario dirigido por los órganos de poder de obreros y campesinos" (MIR, 1965).

Lo anterior, permite interpretar que las diferencias entre la izquierda tradicional representada en la alianza PS-PC-y el MIR respecto de la justicia social, no cristaliza en los fundamentos. Al contrario las coincidencias llaman la atención y nos hace interpretar la noción de justicia social que sustentan, como integrada por un conjunto de necesidades imprescindibles de igualar entre los sectores populares y de trabajadores con respecto del resto de la sociedad. Ello a través de bienes primarios que incluyen derechos sociales, libertades civiles, políticas, que traducidos en petitorios incluyen el salario, las horas de trabajo, la asignación familiar, la reforma agraria, la libertad civil, 
entendida como igualdad política entre las personas y la educación sin distinción y discriminación, entre otros.

Volviendo sobre los trazos que venimos reconstruyendo hasta el momento en lo que respecta a la justicia social, consideramos que materializa la dialéctica entre necesidad y libertad en una relación de totalidad. Traducidos en libertad e igualdad radical como dos momentos indispensables de la "sociedad justa", sabemos que una sin la otra no es posible. Y hablamos de igualdad radical porque asumimos que no se trata de distribuir ciertos recursos o bienes primarios sino de tocar aquellas estructuras sociales que generan y mantienen cualquier tipo de desigualdad.

Las diferencias entre el MIR respecto de la UP, parece ser mas en función del diagnóstico de la situación económica, política y social de Chile, como también de las estrategias impulsadas para alcanzar el poder, y no sustancialmente en las dimensiones, petitorios y valores de lo que debía ser una sociedad justa bajo un sistema donde el capitalismo se hubiera superado.

\section{Conclusión: la justicia como valor, pero ¿qué valores?}

Esperamos haber evitado en este recorrido la objeción historicista respecto de la imposibilidad de testear elementos teóricos a partir de desarrollos históricos concretos. El énfasis puesto en el contexto solo lo hemos entendido como parte de lo que permite explicar algunos desarrollos en ciertos momentos históricos. Nuestra intención ha sido realizar un acercamiento preliminar a lo que -aparentemente- el relato del proceso no deja ver, esto es, la dimensión teórica-valorativa que está detrás del proceso histórico. En ese sentido, concordamos con Moulian cuando afirma que detrás de la empiria existe algo de teoría. Pero, además de conceptos, teorías o "la caja de herramientas", existe el horizonte normativo, el plano de los valores y principios que ayudan a sustentar elecciones y acciones transformadoras de la sociedad.

Una primera idea que surge en esta aproximación, es que la izquierda chilena, materializa -no solo- en los Programas de los Frentes, sino también en los estatutos que rigen a los partidos políticos vertebrales de la izquierda del siglo $\mathrm{XX}$, una noción de justicia social. Existe en ellos una imagen acerca de la sociedad que desean para el Chile de su tiempo, forjada a partir de lo que rechazan en su presente.

Si bien, los hilos que tejen una noción de justicia social y los valores que la sustentan, no son evidentes, ella se entrelaza a una serie de petitorios y declaraciones, que logran mostrar la existencia de ciertos valores que guían (por detrás) las fuerzas para alcanzar, ya sea una sociedad socialista, antiimperialista, antioligárquica y antifeudal, con o sin capitalismo. Más allá de las diferencias de contextos y procesos que singularizan y explican a la izquierda chilena en cada período, nos encontramos con ciertos trazos que se mantienen a lo largo de la historia del siglo XX.

Lo revisado de la izquierda chilena hasta antes del golpe militar, se caracteriza por mostrar programas (cada uno por sí solo) con posturas que abogan por el término del capitalismo. Sin embargo, ambos partidos después de los años 30 forjan alianzas 
estratégicas para llegar al poder, que los obliga a incluir sectores del centro político dejando de lado explícitamente el componente anticapitalista, sin perderlo de vista como intención de futuro.

Los Frentes, como alianzas de diversas orgánicas políticas, traslucen petitorios que en el tiempo se conservan: la preocupación por los salarios, derechos laborales, educación, salud, reforma agraria, industrialización, junto a los derechos y libertades civiles, la libertad de prensa y el desarrollo cultural de los sujetos, hombres, mujeres, niños y etnias. Petitorios claramente que pueden ser comprendidos desde una noción de justicia social en que la dialéctica necesidad y libertad, entre necesidad de igualdad y libertad, se complementan formando una totalidad.

Esto quiere decir, que superar el momento de la necesidad a través de la igualdad de bienes primarios, propicia una "actuar libre". Los bienes primarios a repartir pueden ser interpretados -para la izquierda chilena- como una suerte de recursos a los que deben tener acceso todos, pero especialmente los que han sufrido situaciones crónicas de desigualdad (trabajadores, obreros, mujeres, niños, etnias). Romper o transformar las estructuras sociales que mantienen -para cada momento histórico revisado- la negación de la igualdad y la libertad es la tarea que históricamente identificó a la izquierda y dio sentido a sus alianzas.

La igualdad para la izquierda chilena de los sesenta, es la igualdad radical, absolutamente distante de lo que hoy denominan igualdad de oportunidades (insensible a aquellas desigualdades proporcionadas por las circunstancias de las que las personas no son responsables). La libertad, asimismo, no pudo ser entendida como libertad negativa (o ausencia de coacción externa al individuo), fue especialmente -a nuestro entender- libertad en el sentido positivo o "libertad para" la auto-realización o autodeterminación, para una sociedad emancipada.

Creemos que, reconocer el lugar otorgado a lo normativo y los valores que han inspirado a la izquierda, permite volver a discutir las elaboraciones de acciones y prácticas específicas que las intenta(n)ron materializar. Este ejercicio de ida y vuelta, desde las declaraciones y petitorios hacia el ámbito normativo y viceversa, permite superar la dimensión empírica e instrumental de los primeros, incorporando la dimensión teórica y de fines que sustenta una sociedad justa. Ambos ámbitos se requieren para cristalizar una sociedad justa, ya que no basta con la afirmación de valores para realizar un proyecto emancipatorio, ni solo de instrumentos para llevarla a cabo. Sin duda se requiere de propuestas de intervención, iniciativas y "petitorios" que desencadenen dinámicas sociales en dirección de alcanzar la sociedad justa, pero bajo un bosquejo -a lo menos- de que sociedad justa se desea.

No obstante lo anterior, las necesidades que revelan los petitorios parecen no entrelazarse a la idea de los derechos de los sujetos, ni a una discusión normativa acerca de la igualdad y la libertad. Incluso no se logra reconocer el famoso eslogan marxista "de cada quien según sus habilidades, a cada quien según sus necesidades" como parte de los ejes que guiarían las acciones después de conseguidos estos petitorios, 
por parte de la izquierda. ¿Eso supone que pensemos en un déficit de discusión ética por parte del marxismo y sus aparatos político-partidista? Habrá que profundizar en otro tipo de documentos que nos den luces para la reconstrucción y respuestas de esta dimensión.

Una forma de explicar esta aparente ausencia normativa en la discusión constitutiva de los partidos marxistas, puede estar en la creencia de que la sociedad justa llegaría automáticamente una vez alcanzado el poder, y la experiencia de la Unidad Popular pudo representar aquello, lástima que esta nos dice que una vez alcanzado el poder, remover las bases del capitalismo para generar una sociedad justa (donde la igualdad radical y la libertad se materialicen), significa estar dispuesto para una guerra.

Después de haber indagado en las declaraciones y peticiones de la izquierda constituida a través de los Frentes, surgen claramente algunas preguntas que podrían materializar los cambios que se pretenden en otro tipo de sociedad, ¿qué principios, instituciones y de qué modo se organiza la vida en común en una sociedad no capitalista, (o para la época) antifeudal y antioligárquica? ¿cuál es la idea de justicia que defiende una sociedad socialista, y especialmente esa sociedad que se quería forjar? ¿qué propuestas distributivas son acordes con ese ideario? Tales respuestas no son del todo claras, requieren ser (re)construidas en función de una nueva búsqueda en otros fragmentos de la historia de la izquierda.

En estas preguntas subyace la dimensión ética, y los valores que debe suscribir la izquierda, y con ello, su hilo identitario. No se puede desconocer que la adscripción a ciertos principios y valores, da cuenta también de una tradición. En ese sentido, la noción de justicia que hemos logrado construir, trasluce algunos valores abrazados por la izquierda chilena, los cuales se vinculan a la acción y a la práctica transformadora por y para la igualdad y la libertad. Estos valores implícitamente ayudaron a la izquierda a escoger acciones y petitorios, permitiendo condenar situaciones de su presente, como injustas y gatillar procesos, hoy absolutamente abortados.

\section{Bibliografía}

Amorós, M. Del Frente Popular al Frente del Pueblo. Un período decisivo en la vida de Salvador Allende. 2008. Ubicado en http://www.lapirenaicadigital.es/ SITIO/FRENTEPOPULAR.doc . Revisado el 15 de abril de 2009.

Anderson, P. Spectrum. De la derecha a la izquierda en el mundo de las ideas. Ediciones Akal, Madrid. 2008.

Bambirra, V. Teoría de la Dependencia: una anticrítica. Editorial Era, México. 1978.

Benavides, L. La formación de La izquierda chilena. Relaciones entre el Partido Comunista y el Partido Socialista. Antecedentes Históricos. Documento de Trabajo, No 38. Flacso. Santiago de Chile. 1988. 
Coutinho, C. Marxismo e Política. A dualidade de poderes e outros ensaios. Cortez Editora, 1994. $3^{a}$ edição, São Paulo, Brasil, 2008.

Cruzat, X., Tironi, A. El Pensamiento frente a la Cuestión Social en Chile. En “El Pensamiento chileno en el siglo XX". Eduardo Devés, Javier Pinedo y Rafael Sagredo. FCE, México. 1999.

Devés, E., Díaz, C. El Pensamiento Socialista en Chile. Antología 1893-1933. Ediciones Documentas. Santiago de Chile. 1987.

Devés, E. El Pensamiento en Chile 1950-1973: Ideas Políticas. En "El Pensamiento chileno en el siglo XX". Eduardo Devés, Javier Pinedo y Rafael Sagredo. FCE, México. 1999.

Drake, P. El Socialismo y Populismo. Chile 1936-1973. Instituto de Historia Vicerrectoria Académica Universidad Católica de Valparaiso. Serie Monografías Históricas 6-1992.

Federación Obrera de Chile: Declaración de Principios. Santiago de Chile. 1919. Ubicada en http:/ / www.bibliotecaobrera.cl/?cat=14. Revisada el 10 de febrero de 2009.

Frente Acción de Acción Popular (FRAP): Programa FRAP. En Periódico El Siglo, jueves 1 de marzo de 1956, Santiago de Chile, 1956.

Frente Popular: Programa del Frente Popular. Publicado en diario independiente "La Opinión", jueves 9 de Abril, Santiago de Chile, 1936.

Gazmuri, C. El " 48 " Chileno. Igualitarios, Reformistas, Radicales, Masones y Bomberos. Editorial Universitaria, Santiago de Chile, 1999.

Gazmuri, C. El Chile del Centenario, los ensayistas de la crisis. Ediciones Pontificia Universidad Católica de Chile, Santiago, 2001.

Gazmuri, C. "Los "autoflagelantes" de 1910 Bicentenario. Centenario y reflexión. El Mercurio, publicado el 16 de Diciembre de 2001. Ubicado en http://www. archivochile.com/Historia_de_Chile/otros_artic/HCHotrosart0017.pdf, revisado el 7 de abril de 2009.

Grez, S. De la "regeneración del pueblo" a la huelga general: génesis y evolución histórica del movimiento popular en Chile (1810-1890).

Grez, S. "El escarpado camino hacia la legislación social: debates, contradicciones y encrucijadas en el movimiento obrero y popular (1901-1924). Ubicado en http:/ / www.bibliotecaobrera.cl/wp-content/uploads/2009/03/legislacionsocial.pdf . Revisado el 15 de abril de 2009. 
Grez, S. "Los anarquistas y el movimiento obrero. La alborada de "la idea" en Chile, 1893-1915". Editorial LOM, Santiago de Chile, 2007.

Gómez, M. S. Factores Nacionales e Internacionales de La Política Interna Del Partido Comunista de Chile (1922-1952). En "El Partido Comunista en Chile: estudio multidisciplinario". Alberto Varas compilador. Ediciones CESOC, Santiago de Chile, 1988.

Loyola, M. "Los destructores del Partido": notas sobre el reinosismo en el Partido Comunista de Chile. Revista Izquierdas, año 1, $\mathrm{N}^{\mathrm{o}} 2$. Disponible en http:// www.izquierdas.cl/html/numero_2/Reinosismo.pdf. Revisado el 12 de abril de 2009.

Mandel, E. O lugar do Marxismo na Historia. Xama Editora. São Paulo, Brasil, 2001.

Massardo, J. Apuntes para una relectura de la historia del marxismo en América Latina. En El Comunismo: otras miradas desde América Latina. Elvira Concheiro, Massimo Modonesi, Horacio Crespo coordinadores. Colección Debate y Reflexión. Universidad Autónoma de México, 2007.

Movimiento de Izquierda Revolucionaria: Programa MIR. Congreso de Fundación 1965. En Miguel Enríquez y el Proyecto Revolucionario en Chile. Discursos y documentos del Movimiento de Izquierda Revolucionaria, MIR. Pedro Naranjo, Mauricio Ahumada, Mario Garcés y Julio Pinto. Centro de Estudios Miguel Enríquez. Editorial LOM, Santiago de Chile, 2004.

Modonesi, M. El Comunismo hoy. En El Comunismo: otras miradas desde América Latina. Elvira Concheiro, Massimo Modonesi, Horacio Crespo coordinadores. Colección Debate y Reflexión. Universidad Nacional Autónoma de México. México. 2007.

Moulian, T. Fracturas. De Pedro Aguirre Cerda a Salvador Allende (1938-1973). Editorial LOM, Santiago de Chile, 2006.

Naranjo, P., Ahumada, M., Garcés, M., Pinto, J. Miguel Enríquez y el Proyecto Revolucionario en Chile. Discursos y documentos del Movimiento de Izquierda Revolucionaria, MIR. Centro de Estudios Miguel Enríquez. Editorial LOM, Santiago de Chile, 2004.

Partido Comunista de Chile. Estatutos del Partido Comunista. Editorial Antares. Santiago de Chile. 192--.

Skinner, Quentin: Significado y Comprensión de las Ideas. En Revista de Historia Intelectual, Prisma. $N^{\circ}$ 4, 2000, pp. 149-191. 
Unidad Popular. Programa de Gobierno de la Unidad Popular. 1969. En Salvador Allende. La vía Chilena hacia el Socialismo. Mario Garcés. Editorial Fundamentos, Madrid, España, 1998.

Vitale, Luis: "Contribución a una Historia del Anarquismo en América Latina". Instituto de Investigación de Movimientos Sociales "Pedro Vuskovich". Santiago. Chile, 1998. Disponible en http://www.scribd.com/doc/8944386/Luis-Vitale-Contribucion-a-una-historia-del-anarquismo-en-America-Latina. Revisado el 15 de febrero de 2009.

Witker, A. Historia documental del PSCH: 1933-1993. Signos de Identidad. IELCO. Santiago de Chile, 1993. 